(c)

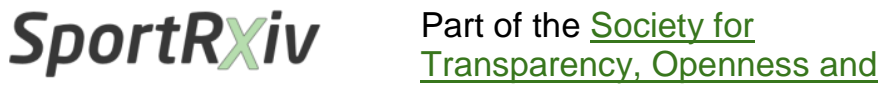 \\ Replication in Kinesiology (STORK)}

\section{Preprint}

not peer reviewed

Received: 10th July 2021

Supplementary materials:

For correspondence:

lanburton_10@hotmail.co.uk

\title{
A Critical Review of Eating Disorders in Female Athletes and Evidence-based Interventions for Sports Coaches
}

Ian Burton MSc, CSCS

Specialist Musculoskeletal Physiotherapist, NHS Grampian

Please cite as: Burton, I. (2021). A Critical Review of Eating Disorders in Female Athletes and Evidence-based Interventions for Sports Coaches

SportRxiv doi: 


\section{Contents}

Key to Technical terms and Abbreviations

Abstract

1. Introduction

2. - Methodology

3. - Critical Review of Eating Disorders in Female Athletes

3.1 - Clinical Eating Disorders

3.2 - Subclinical Conditions

3.2.1 - Disordered Eating \& the Female Athlete Triad

3.2.2 - Relative Energy Deficiency in Sport

3.2.3 - Anorexia Athletica

3.3 - Risk Factors for Eating Disorders in Female Athletes

3.4 - Genetics \& Personality

3.5 - Sociocultural Risk Factors

3.6 - Sport-related Risk Factors

3.7 - Weight Pressures \& Competitive Thinness

3.8 - Body Image Issues, Revealing Sport Uniforms \& Other Factors

3.9 - Prevalence of Eating Disorders in Female Athletes

3.10 - Are Female Athletes at Increased Risk?

3.11 - Are Female Athletes in Certain Sports at Increased Risk?

3.12 - Does Competition Level Predict Eating Disorders?

3.13 - Methodological Issues

4. - Evidence-based Interventions for Eating Disorders in Female Athletes 
4.1 - Intervention \& Prevention programs

4.1.2 - N.I. \& U.K.

4.2 - Screening Interventions

4.3 - Pre-participation Examinations \& Symptom Checklists

4.4 - Treatment Interventions

5. - The Role of the Sports Coach in Eating Disorder Intervention

5.1 - The Role of the Sports Coach in Eating Disorder Intervention

5.2 - Are Coaching Behaviours a Risk Factor for Eating Disorders?

5.3 - Is there a Lack of Knowledge \& Education for Sports Coaches?

5.4 - Are Coach Education Interventions Effective?

6. - Conclusion and Recommendations

$6.1-$ Conclusion

6.2 - Recommendations for Sports Coaches

6.3 - Limitations

References

Appendices

\section{Abbreviations}

FAT - Female Athlete Triad

AA - Anorexia Athletica

AN - Anorexia Nervosa

BN - Bulimia Nervosa

BED - Binge Eating Disorder 
EDNOS - Eating Disorder not otherwise specified

OSFED - Other Specified (or Unspecified) Feeding or Eating Disorder

ED - Eating Disorders

RED-S - Relative Energy Deficiency in sport

CBT - Cognitive Behavioural Therapy

ATHENA - Athletes targeting Healthy Exercise and Nutrition Alternatives

DE - Disordered Eating

RTP - Return to Play

DSM-V - Diagnostic and Statistical Manual of Mental Disorders $5^{\text {th }}$ Edition

BMD - Bone Mineral Density

PPE - Pre-participation Examination

UK - United Kingdom

NCAA - National Collegiate Athletic Association

IOC - International Olympic Committee

ACSM - American College of Sports Medicine

$\mathrm{EBI}$ - Evidence-based Interventions

N.I - Northern Ireland 


\section{$\underline{\text { Abstract }}$}

Eating disorders (ED) are serious mental disorders, which can have serious health consequences and high mortality rates. Due to facing unique risk factors female athletes have increased susceptibility for ED. Female athletes are also at risk for subclinical conditions such as the Female Athlete Triad. There is a dearth of studies on preventing and identifying ED in female athletes and the role and responsibility of the sports coach is unclear. This study aimed to address the questions of whether female athletes are at increased risk for ED, what interventions currently show promise and what is the role of the sports coach in the intervention process. The study was based on a systematic review of relevant literature retrieved through PubMed and Sports Discus databases.

Despite heterogeneity in prevalence studies, findings suggest that female athletes are at higher risk than male athletes and non-athletes and those in elite level sports or sports categorised as lean, aesthetic, endurance and weight-class are at increased risk for clinical and subclinical ED. Risk-factors unique to the sports environment such as weight pressures, competitive thinness and revealing uniforms, may lead to increased risk in female athletes. Despite a dearth of studies on interventions for ED in sport, findings suggest that primary prevention programs based on educating athletes such as ATHENA show most promise in prevention. Secondary prevention should focus on early identification using athlete-specific screening tools. Symptom checklists and pre-participation examinations can also assist coaches in early identification. Psychotherapy interventions such as CBT have had the best results for treatment.

Sports coaches' play a critical role in, early identification, referral, management and prevention of ED in female athletes. However, current findings suggest that many coaches lack knowledge about ED and require education to be able to intervene successfully in female athletes with ED. Inappropriate coaching behaviours have also been found to act as an additional riskfactor for ED. Recommendations for sports coaches in N.I. are provided to assist them in successful intervention, management and return to play of female athletes with ED.

Key words: Eating Disorders, Sports, Coaches, Female Athlete Triad, Prevention. 


\subsection{Introduction}

Over the last 30 years there has been a substantial growth in female participation in sport, due to social changes which have created a positive attitude towards female athletic participation (Marquez \& Molinero, 2013). In the United States (U.S) the escalation of female sports participation can be attributed to the passage of Title IX in 1972, which bans gender discrimination in sport. Since then, female athletic participation has increased over $900 \%$ in high school sport and $450 \%$ in collegiate sport (Javed et al., 2013). In the U.K., female sport participation also continues to increase; currently 6.9 million women take part in sport at least once a week (Sport England, 2011). There are many potential health benefits for females who participate in sport, including physically, psychologically and emotionally (Troy et al., 2006). Female athletes have been shown to have higher self-esteem, less depression, perform better in school and engage in less high-risk behaviours such as drug use (Hoch et al., 2011). Despite these potential benefits, female athletes are not immune from health harming behaviours and appear to be at increased risk of developing eating disorders (ED) such as Anorexia nervosa and Bulimia nervosa (Smolak et al., 2000).

ED are of great concern because of their associations with physical (Swanson et al., 2011) and mental health risks (Presnell et al., 2009) as well as impaired performance in athletes (Torstveit \& Sundgot-Borgen, 2013) and shorter sports careers (Currie, 2010). Athletes in certain sports appear to be at high risk for developing ED due to their focus on weight categories, a thin appearance, low body fat or intensive exercise, such as endurance sports (Greydanus et al. 2010). Sports such as gymnastics and diving are labelled 'leanness-demanding' due to their preference for a lean physique and because they are aesthetically judged (Ackland et al., 2012; Meyer et al., 2013). Prevalence data indicate that clinical ED are significant problems for up to $46 \%$ of elite females in lean sports and almost $20 \%$ in non-lean sports (Torstveit, Rosenvinge, \& SundgotBorgen, 2008). Subclinical eating conditions unique to the female athlete have also emerged such as Anorexia Athletica and the Female Athlete Triad (De Souza et al., 2014). As a result, the relationship between sport and ED has been receiving increasing attention in both academia and the media (Coelho et al., 2014).

Athletes comprise a unique sub-population of ED patients, who face risks unique to the sport environment. Therefore, specialized approaches to identification, management, treatment and prevention are required (Thompson \& Sherman, 2010). However, there is a dearth of studies on evidence-based interventions specifically designed for the unique needs of athletes with ED 
(Hoch et al., 2011). There is also a need for athlete specific screening tools that capture the unique characteristics of female athletes (Knapp et al., 2014). Many authors agree that a multidisciplinary team approach to treatment and management of ED in athletes is the preferred method of care (Joy et al., 2003). This team should include both health professionals and sport personnel such as coaches (De Souza et al., 2014). It has been suggested that sports coaches are in an ideal position to identify ED (Sherman, DeHass, Thompson, \& Wilfret, 2005). It's unlikely that any prevention program regarding athletes can be successful without the support, endorsement and participation of coaches (Thompson \& Sherman, 2010). However, many coaches still lack proper education regarding ED in athletes and there is a need for formal education programs (Bonci et al., 2008). In Northern Ireland (N.I) there is a significant lack of information available to sports coaches to assist in ED intervention.

Despite the increased research interest in ED in sport, many questions remain unanswered. Given the serious consequences of ED, this study aims to address key unresolved issues. The first aim is to establish the scope of the problem of ED in female athletes by evaluating the literature on the prevalence rates and risk factors specific to the sports environment. Secondly, the literature on successful evidence-based interventions for ED in sport will be evaluated. Thirdly the role of the sports coach in the intervention process will be examined and the need for education highlighted. Finally, recommendations to assist sports coaches in N.I in intervening in athletes with ED will be provided based on the findings in the literature.

\subsection{Methodology}

As this was a theoretical library-based study aiming to review the literature on ED in female athletes and evidence-based interventions for sports coaches, primary research methods such as qualitative and quantitative were not appropriate. The study was based on a systematic review. A systematic review is a literature review that is designed to locate, appraise and synthesize the best available evidence relating to a specific research question to provide informative and evidence-based answers. The findings can then be combined with professional judgement to make decisions regarding intervention delivery or changes to policy. Systematic reviews are considered the gold standard way to synthesise the findings of many studies investigating questions related to healthcare (Dickson, Cherry, \& Boland 2014). 
There are nine steps in the systematic review process: Identifying the review question and protocol; Literature searching; Screening titles and abstracts; Obtaining papers; Selecting full-text papers; Quality assessment; Data extraction; Analysis and synthesis; Writing up and editing. This review is designed to systematically interrogate the published literature to address the issues of ED in female athletes and the best interventions for sports coaches. After identifying the review question, the next step is to identify the inclusion criteria for the review. Inclusion criteria identify specific attributes a study must have if it is to be included. A common way to develop inclusion criteria is to generate a PICOS (Population, intervention, comparator, outcome and study design) table (Cherry \& Dickson 2014). The following PICOS table was used for assessing the evidence for ED interventions in this study.

Review question: A critical review of eating disorders in female athletes and evidence-based interventions for sports coaches in N.I.

Population: $\quad$ Adult and adolescent female athletes.

Intervention: $\quad$ Any intervention to identify or prevent ED.

Comparator: $\quad$ The stated interventions compared with each other, placebo, control or no intervention.

Outcomes: $\quad$ Successful identification or prevention of ED.

Study design: $\quad$ All studies.

After identifying the inclusion criteria, the author conducted searches of literature on Medline via PubMed, as this is the largest most robust database of peer-reviewed medical literature. Additional searches were conducted on Sports Discus, which is the most comprehensive database for sports studies. The researcher also reviewed bibliographies of retrieved articles to find those which had not being identified in searches. Significant earlier studies identified through articles, were also included. Searches were confined to the English literature and focused on published studies from the last ten years, to ensure studies were relevant and up to date. A combination of free-text words and medical subject headings (MeSH) were used in the search strategy to improve the accuracy of results (Dundar \& Fleeman, 2014). Search terms included 'Eating Disorders', 'Female Athlete Triad', 'Prevention', 'Sport' and 'Coaches' in order to find appropriate studies. 
All titles and abstracts identified via searches were screened using inclusion criteria and full-text papers of eligible articles were obtained. Studies meeting the criteria were selected for review and results were reported using PRISMA (Preferred reporting items for systematic reviews) guidelines. PRISMA is an evidence-based minimum set of items that help improve reporting of systematic reviews (Liberati et al., 2009). Selected studies were then examined for 'quality' via a quality assessment, to ensure they are reliable and relevant. Quality refers to the degree to which a study employs measures to minimize bias and error in its design, conduct and analysis (Greenhalgh \& Brown, 2014). The next step was to identify and extract relevant data from each study. Data extraction is the process whereby relevant data are taken from included studies and stored in a data extraction form (Fleeman \& Dundar, 2014). The final stage involved critical interpretation, analysis, discussion and conclusion of the findings in relation to the review question.

\subsection{Critical Review of Eating Disorders in Female Athletes}

This chapter will review the literature on clinical and sub-clinical ED in female athletes. After reviewing the specific disorders, general and sport-specific risk factors for ED will be examined. Finally studies on the prevalence of ED in sport will be reviewed in an attempt to ascertain if female athletes are at increased risk for ED.

\subsection{Clinical Eating Disorders}

ED are psychiatric conditions characterized by disturbed eating behaviours and attitudinal distortions. They can have life-threatening consequences and therefore require clinical treatment (APA, 2013). The recently updated Diagnostic and Statistical Manual of Mental Disorders, $5^{\text {th }}$ edition (DSM-V) recognises the clinical ED as Anorexia Nervosa (AN), Bulimia Nervosa (BN), Binge Eating disorder (BED) and Other specified (or unspecified) feeding of eating disorder (OSFED) (APA, 2013). The diagnostic criteria for these disorders are listed in appendix 1-4. ED have some of the highest mortality rates among mental illnesses (Marquez, 2008). Mortality rates of $5.9 \%$ have been reported (Currie, 2010) and as high as $10.5 \%$ (Birmingham et al., 2005). In the U.K 1.6 million people have an ED, with $90 \%$ of that female. It is estimated that of those with ED, $10 \%$ have $\mathrm{AN}, 40 \%$ have $\mathrm{BN}$ and the rest fall into OSFED, including BED (Adult Psychiatric Morbidity Survey, 2007). In N.I., evidence indicates that approximately 340-1,700 people suffer from AN, and approximately 17,000 suffer from BN (Department of health, 2002). 
ED in athletes typically begin with voluntary food restriction which progresses to chronic dieting and pathological eating, accompanied by weight control behaviours such as excessive exercise (Torstveit \& Sundgot-Borgen, 2013). The disorders have many common features and athletes often move between diagnoses (Sundgot-Borgen \& Torsveit, 2010). Many athletes who previously would have been diagnosed with ED not otherwise specified (EDNOS) will now receive a diagnosis with greater clinical service as a result of the new categories such as OSFED and BED and the changed criteria for AN and BN (Call et al., 2013). ED can have serious health consequences and a negative effect on sport performance by causing low energy availability, excessive loss of fat and lean mass, dehydration, and electrolyte disturbance (El Ghoch et al., 2013). A full discussion of the effects of ED on health and sports performance is beyond the scope of this study, however a summary of effects can be found in appendix $5 \& 6$.

\subsection{Subclinical Conditions}

Female Athletes can also suffer from eating problems which are not clinical ED but can still have serious health and performance consequences. They are often referred to as subclinical conditions and include Disordered Eating (DE), Anorexia Athletica (AA), the Female Athlete Triad (FAT), and Relative Energy Deficiency in Sport (RED-S).

\subsubsection{Disordered Eating \& the Female Athlete Triad}

The term DE was first used by the American college of sports medicine (ACSM) and refers to a wide spectrum of harmful eating behaviours used in order to achieve a lean appearance or lose weight (Nattiv et al., 2007). DE behaviour tends to occur on a spectrum or continuum and athletes can traverse from one condition to another (Tozzi et al., 2005). The continuum begins with dieting and restrictive eating, abnormal eating behavior, and finally clinical ED (Torstveit \& SundgotBorgen, 2013). DE is also one of three interrelated components which originally formed the FAT, along with amenorrhea and osteoporosis. The term was first introduced by the ACSM in 1997 (Otis et al., 1997). In 2007, the ACSM updated the FAT to include a spectrum of dysfunction involving energy availability, menstrual function and bone mineral density (BMD) (appendix 7). Athletes are distributed along a spectrum between health and disease with the pathological end manifesting in clinical ED, functional hypothalamic amenorrhea and osteoporosis (Nattiv et al., 2007). 
Energy availability is defined as the amount of unused dietary energy remaining after exercise training for all other metabolic functions (Loucks, 2007). When values fall below $30 \mathrm{kcal}$ per kg of free fatty mass per day, reproductive function and bone formation are reduced to restore energy balance leading to impaired skeletal and reproductive health (Manore et al., 2007). Low energy availability, reduced metabolic hormones and supressed oestrogen release can synergistically impair bone health, leading to reduced BMD (Mallinson \& De souza, 2014) and increased risk of stress fractures and osteoporosis (Barrack et al., 2014). Medical complications of the FAT can involve the cardiovascular, endocrine, reproductive, skeletal, gastrointestinal, renal, and central nervous systems (Nattiv et al., 2007). Due to the potential severity of these health consequences it's important that those involved with athletes, particularly coaches, are cognizant of the risks of the syndrome (Nazem \& Ackerman, 2012).

Recently many studies from around the world have documented the prevalence of the FAT at various competition levels (appendix 8 ). Despite wide variances in findings, there is consistently a small but significant prevalence rate of the triad, suggesting it is a global problem in sport. However varying methodologies used in these studies to classify triad components prevents meaningful comparisons (Zach, Machin, \& Hoch, 2011). A recent meta-analysis of 65 studies by Gibbs et al. (2013), involving 10,498 athletes found that 0\%-16\% exhibited all three Triad conditions.

\subsubsection{RED-S}

In early 2014 the International Olympic Committee (IOC) announced the new term RED-S as a

broader, more comprehensive term for the FAT, which points to the complexity involved and that males are also affected (Mountjoy et al., 2014). The aetiological factor causing the syndrome is energy deficiency, which affects many aspects of physiological function, health and athletic performance and not just a 'triad' of conditions (appendix $9 \& 10$ ). Proponents of the FAT have claimed the new terminology is insufficiently supported by scientific research and the FAT has more than 30 years of published evidence to support its existence and should remain a focus of scientific inquiry (De Souza et al., 2014).

\subsubsection{AA}

AA is a condition characterized as involving an intense fear of gaining weight or becoming fat despite being underweight. There is weight loss of at least $5 \%$ of expected body weight, usually 
achieved by reducing total energy intake often with extensive exercising. These athletes also frequently engage in binge eating and the use of pathogenic weight control methods (SundgotBorgen, 1993). These athletes may display features of AN without meeting diagnostic criteria (Sudi, 2004). Using these criteria, Herbrich et al. (2011) found that $5.8 \%$ of a sample of athletes met the diagnosis for $A A$, while only $1.9 \%$ were diagnosed with clinical $E D$, suggesting $A A$ may be more prevalent. Wheatley et al. (2012) have recently summarized the key components of AA and the FAT in comparison to AN and EDNOS and proposed a new unified framework under the term 'female energy deficiency' to reconcile overlapping definitions.

\subsection{Risk Factors for Eating Disorders in Female Athletes}

The identification of risk factors for ED is necessary for identifying those at highest risk, developing intervention programs and setting public policy (Striegel-Moore \& Bulik, 2007). While factors such as genetics and sociocultural influences can affect anyone, athletes also face factors unique to the sport environment; potentially placing them at higher risk for ED. However, sport should not be avoided on this basis, as it can have a positive effect on psychological well-being (DiBartolo \& Shaffer, 2002). Sport participation may even help prevent ED (Morse, 2008); therefore, sport should not be avoided but rather the associated risk factors. For example, a study compared runners from Kenya and the U.K. and non-sport controls from both countries. Whereas $19.5 \%$ of the UK runners had a current or previous ED, the Kenyan runners had the lowest numbers of ED of the four groups. It appears that running does not increase risk for an ED, but that risk is multifactorial and includes factors such as culture, sport and the person's individual factors (Hulley et al., 2007). A cumulative number of risk factors are also associated with an increased risk of the FAT (Gibbs et al., 2014). An etiological model focusing on the psychosocial factors that increase risk of ED in female athletes has been proposed by Petrie \& Greenleaf (2007). The Model (Appendix 11) consists of eight inter-related risk factors and variables which can moderate the relationships between the factors.

\subsection{Genetics \& Personality}

The findings of genetics studies suggest that ED may run in families due to genetic factors (Mazzeo et al., 2006). Studies on families and twins have found a strong heritable component for ED, with heritability estimates as high as $76 \%$ for AN (Klump et al., 2001) and $83 \%$ for BN (Bulik 
et al., 1998). However, a genetic predisposition is just one factor and will require interaction with other factors to precipitate an ED in an individual. Personality traits such as perfectionism also appear to play a role. The personalities of those with ED are thought to be intrinsically perfectionistic, as are many athletes, suggesting a relationship to the higher levels of ED in this group (Forsberg \& Lock, 2006). Insecure attachment styles also influence athletes' eating psychopathology via their impact on self-esteem, depression, and self-critical perfectionism (Shanmugam et al., 2012).

\subsection{Sociocultural Risk Factors}

The evidence for a sociocultural model for ED is provided by the increasing prevalence of females diagnosed coinciding with the decreasing size of the ideal body for women. Prevalence is higher in western cultures valuing female thinness and there is clearly a relationship with eating problems and internalization of the thin ideal (Striegel-Moore \& Bulik, 2007). This internalization can lead to body dissatisfaction and DE (Petrie \& Greenleaf, 2007). The internalization of the sociocultural body standards provides a mechanism through which exercise levels are associated with ED (Jankauskiene \& Pajaujiene, 2012). Conversely, a low prevalence of ED and dieting has been found in Chinese athletes, partly due to the lack of a sociocultural imposed desire to be thin (Okano et al., 2005).

It has been suggested that this idealization of thinness is amplified by the media and promoted by family and peers (Stice, 2002). Studies have found that this amplification of the thin ideal by the media to have a negative effect on body image, eating attitudes and behaviours (Becker \& Fay, 2006). Pressures to be thin can increase ED risk and body dissatisfaction (Tylka \& Subich, 2004). Studies on risks associated with the family also imply a role in eating pathology (Annus et al., 2007). Research has also shown that Pressures from peers to be thin can increase potential eating problems (Stice, Maxfield \& Wells, 2003). Social comparisons with thin peers can lead to body dissatisfaction (Krones et al., 2005) leading to ED (Troop et al., 2003). Social media sites, such as Facebook, merge two factors that influence risk for ED: media and peers. Recent studies have found frequent Facebook use is associated with greater DE (Mabe et al., 2014). 


\subsection{Sport-related Risk Factors}

Genetic factors may provide the potential for ED and their interaction with sociocultural factors can lead to their development. Specific factors and risks in the sport environment may exacerbate this situation by encouraging an unhealthy focus on body shape and weight, making female athletes particularly susceptible (Petrie \& Greenleaf, 2007). Although there has yet to be any longitudinal studies regarding risk factors in the sports environment for ED some factors still need to be considered due to their potential serious consequences for athletes (Jacobi, 2005).

\subsection{Weight Pressures \& Competitive Thinness}

Even though research showing leanness enhances sport performance has been equivocal (Thompson \& Sherman, 2010) many athletes and coaches believe carrying extra weight can negatively affect athletic performance. Therefore, pressure from coaches has been placed on athletes, particularly in lean sports to lose weight, to enhance performance (De Bruin et al., 2007). This added pressure could precipitate harmful eating behaviours and lead to or exacerbate ED.

Many women, particularly athletes, may compare themselves with other women, regarding attractiveness and thinness. This tendency for body comparisons is often referred to as 'competitive thinness' and can lead to body dissatisfaction (Krones et al., 2005) and may lead to excessive exercise (Wasilenko et al., 2007). Highly ego-oriented athletes will want to perform better and will compare body size with opponents and teammates. For example, gymnasts tend to be highly ego-oriented and tend to have more ED than less ego-oriented athletes (De Bruin et al., 2009). Social pressures and eating behaviours within the team setting can be construed as normal behaviour and therefore spread among the team, a term coined 'social contagion' (Crandall, 1988).

It's been found that athlete's DE behaviour can be associated with their perception of how teammates are excessively dieting (Engel et al., 2003). A major source of pressure about body image and weight comes from fellow athletes and the team environment may stress thinness and dieting, therefore perpetuating DE (Filaire et al., 2007). A recent study found that ED where positively associated with dieting advice received from teammates (Kroshus et al., 2014). An association between a high drive for thinness and increased risk of ED and the FAT has also been found (Gibbs et al., 2011). Some ED symptoms may also be overlooked or even desired in the 
sports environment, such as dieting and weight loss, menstrual dysfunction and excessive exercise (Thompson \& Sherman, 2010).

\subsection{Body Image issues, Revealing Sport Uniforms \& Other Factors}

An individual's perceptions, attitudes and experiences about their body, particularly its appearance, are referred to as their 'body image' (Cash, 2002). The development of ED is associated with impaired body image and dissatisfaction (APA, 2013). In elite athletes, the strongest ED predictor is body image dissatisfaction (Francisco et al., 2013). An increased sociocultural influence is associated with greater body image dissatisfaction, leading to restrictive dieting and eventually ED (Vaquero-Cristóbal, 2013). High levels of body dissatisfaction have also been found in elite and non-elite athletes often leading to ED (Torstveit et al., 2008). Revealing sport attire or uniforms in certain sports has been found to make athletes more body conscious and dissatisfied with their body shape (Greenleaf, 2002). Athletes may find uniforms a source of pressure attributed to body image and weight (SooHoo, Jamieson, \& Gill, 2007). This body image dissatisfaction from uniforms appears to increase risk for ED development in female athletes (Torres-McGehee, 2012).

Athletes with injuries may be at increased risk of ED, especially if they are unable to participate. The athletes may be concerned with weight gain due to inactivity and depression may also occur (Bulik \& Allison, 2002). Symptoms of overtraining can be like those of ED, such as depression, fatigue and amenorrhea (Raglin \& Wilson, 2000). Studies have found that high rates of female athletes in many sports have suffered sexual abuse in the sports environment (Fasting, Brackenridge \& Sundgot-Borgen, 2004), associated with ED development (Brewerton, 2005).

\subsection{Prevalence of Eating Disorders in Female Athletes}

As previously highlighted, female athletes may be at increased risk for developing ED as they face the same risk factors as the general population as well as risks specific to the sports environment. Individual estimates of DE in female athletes' range from 18-45\% (da Costa et al., 2013) and clinical ED in female athletes range from 0-48\% (Gibbs et al., 2013). In female athletes, prevalence rates of AN ranging from $0-2 \%$, BN from $1-6 \%$ and EDNOS at $8 \%$ have been reported (SundgotBorgen \& Torstveit, 2004). Higher prevalence of subclinical ED in female athletes (14.5\%) than 
clinical ED (5.1\%) has also been found (Sandford-Martens et al., 2005). Toro et al. (2005) found the proportion of athletes suffering from ED was five times higher than in the general population (22.6\% vs. $4.1 \%)$. However, others have found no significant difference in the percentage of ED between athletes and controls (Coelho et al., 2010). The heterogeneity in findings implies that sports participation is only an additional risk factor in a complex combination of risk factors for ED (Smolak et al., 2000).

\subsection{Are Female Athletes at Increased Risk?}

The lifetime prevalence of ED in athletes has been found to be up to three times higher among females than males (Hudson et al., 2007). The prevalence of ED has been found to vary from 0$19 \%$ in male athletes and 6-45\% in female athletes (Bratland-Sanda \& Sundgot-Borgen, 2013). In a study on U.S collegiate female athletes, $7 \%$ were found to have a clinical ED (Reel et al., 2007) whereas a study on male collegiate athletes found only $1 \%$ had an ED (Petrie et al., 2007). A study on elite athletes reported similar findings, with $20 \%$ of elite Norwegian female athletes having an ED compared to $8 \%$ of males (Sundgot-Borgen \& Torstveit, 2004). These findings suggest females are at higher risk than males.

\subsection{Are Female Athletes in Certain Sports at Increased Risk?}

Athletes in sports that emphasize a thin or lean physique, or a low weight seem to be at an increased risk for ED (Hagmar et al., 2008). Lean sports tend to be classified as weight-class (weight-dependent), aesthetic (judged), or endurance sports (Beals, 2004). Torstveit et al. (2008) found that more athletes in lean sports (46.7\%) had clinical ED than athletes in nonleanness sports (19.8\%) and controls (21.4\%). Athletes competing in sports that emphasise thinness or a specific weight have also been found to be at increased risk for the FAT (Torstviet \& Sundgot-Borgen, 2005).

Weight-class sports appear to have a higher risk of ED than non-weight class sports (Hagmar et al., 2008). Rowing coaches have reported more females with ED than coaches from any other sport (Sherman et al., 2005). Rouviex et al. (2007) found $25 \%$ of female judo athletes were at risk for ED whereas no males were judged at risk. In female equestrian athletes, ED prevalence has been found to be as high as $42 \%$ (Torres-McGehee, 2011). A lifetime prevalence of $4.5 \%$ of $\mathrm{AN}, 1.8 \%$ for $\mathrm{BN}$ and $11.7 \%$ for EDNOS was found among Israeli female athletes in aesthetic sports such as gymnastics, dancing and synchronized swimming (Bachner-Melman et 
al., 2006). Recently, the prevalence of ED in aquatic sports has been found to range from $18-45 \%$ in female athletes (Melin et al., 2014). Endurance sports also appear to have increased susceptibility; one study found that $25.7 \%$ of elite Norwegian female endurance athletes had an ED (Torstveit et al., 2008). Hulley \& Hill (2001) found that $16 \%$ of female distance runners had an ED, while Thompson (2007) found that $19.4 \%$ of female cross-country runners had a current or previous ED.

Female athletes in sports which are not specifically categorised as 'lean' may also be at risk. Among elite female athletes in non-lean sports, $55.3 \%$ were found to be at risk for the FAT (Torstveit \& Sundgot-Borgen, 2005) and clinical ED have been reported in $19.8 \%$ of elite female athletes in non-lean sports (Torstveit et al., 2008). In one study $24 \%$ of elite female soccer players and $29 \%$ of elite handball players were found to have ED (Sundgot-Borgen \& Tortsveit, 2007).

\subsection{Does Competition Level Predict Eating Disorders?}

Higher levels of sport and competition can have increased pressure to perform, providing an environment more conducive to the development of ED. As previously highlighted, many elite female athletes' do have ED, which raises the question: do higher competition levels have higher prevalence of ED? It has been suggested that prevalence is higher in elite female athletes (Sundgot-Borgen \& Torstveit, 2010) as they seem to present in more advanced stages of the DE continuum (Coelho et al., 2010). A recent study found the prevalence of ED among elite female athletes and controls was estimated to be $7.0 \%$ versus 2.3\% (Martinsen \& Sundgot-Borgen, 2013). A higher prevalence of ED was also found in Japanese runners and gymnasts who competed at higher levels (Okano et al. 2005). A recent study of elite female athletes in Australia found that $22.8 \%$ had ED (Gulliver et al., 2014).

However, some studies have found that low competition levels do not offer greater protection. For example, Spanish athletes at higher levels of sport had lower levels of ED compared to those in lower levels of sport (Toro et al., 2005). In one study, $26.6 \%$ and $20.6 \%$ of non-elite athletes and gym users had ED (Rivaldi et al., 2003). Those involved in recreational activities have been found to have higher risk for ED than competitive athletes in some studies (Levitt, 2008; Sandford-Martens et al., 2005). This suggests that high level sport is not a definitive risk factor (Reinking \& Alexendar, 2005). Due to the heterogeneity of findings, a definitive conclusion about the groups at highest risk for ED remains to be elucidated (Coelho et al., 2010). 


\subsection{Methodological Issues in Prevalence Studies}

Certain factors may help explain the wide-ranging prevalence of ED found in studies on athletes. Classification issues include the use of different diagnostic criteria and measures of assessing ED (Beals, 2004). Researchers may also use different measurement instruments, contributing to the wide variances, thus only measures that have been validated and standardized with current diagnostic criteria should be used for research (Petrie \& Greenleaf, 2007). Studies on ED in athletes typically use small, non-representative samples of convenience, typically focused on elite female athletes (Patel et al., 2003). There is also inconsistency regarding sport classification such as lean, non-lean and aesthetic (Thompson \& Sherman, 2010). Therefore, it is difficult to draw accurate conclusions. Future research should address these methodological limitations to provide more accurate data regarding the scope of the problem in athletes.

\subsection{Evidence-based Interventions for Eating Disorders in Female Athletes}

Although the importance of preventing ED in female athletes is regularly discussed and recommended in the literature, there is a lack of evidence-based prevention studies involving this high-risk group (Thompson \& Sherman, 2010). Educational programs are the best method for primary prevention of ED. For secondary prevention, early identification is essential and should be performed by validated screening measures (Coelho et al., 2014). The first prevention programs aimed to change attitudes and behaviours, typically in a group setting by providing didactic psychoeducation. It was thought that educating athletes about the adverse effects of ED would prevent harmful weight control behaviours. However, these programmes were not always effective (Stice \& Shaw, 2004). Recent intervention programs aimed at female athletes have used interactive groups focusing on risk factors predictive of ED. These programs have been found to be more effective than general programs (Stice et al., 2000). Coaches are often involved in these programmes, so it's important they have an understanding of how they work.

\subsection{Intervention \& Prevention Programs}

Athletes Targeting Healthy Exercise and Nutrition Alternatives (ATHENA) is a universal selective program, which is scripted, coach facilitated, and peer led. Its target is female school participants, 
and it aims to decrease risk factors for ED. The curriculum aims to build skills to control mood, counter media influences and provide education on nutrition and exercise (Elliot et al., 2004). ATHENA has been found to significantly decrease target risk factors and promote healthy lifestyles, deterring ED (Elliot et al., 2006). However, these reductions in eating pathology did not continue after 1-3-year follow-up (Elliot et al., 2008). ATHENA appears to be a primary prevention program with a stronger effect on reducing intentions than behaviours (Ranby et al., 2009).

Dissonance based prevention (DBP) programmes have had positive results in reducing ED (Stice et al., 2008). The Female Athlete Body Project is a long-term programme using a cognitivedissonance approach to prevent ED. Findings show that participants had decreases in thin-ideal internalization, negative effect, eating pathology and body dissatisfaction after the intervention, with changes maintained at 6-week follow-up (Stice et al., 2003). In a cognitive dissonance-based ED intervention, athletes engage in experiences that contradict and challenge their beliefs about the thin ideal (Levine \& Smolak, 2007). A recent study compared the effectiveness of an athletemodified (AM) peer-led version of DBP and a healthy weight intervention (HWI) at reducing ED risk factors in 157 female U.S college athletes. Both groups had positive results, including reduction in eating pathology at 6 and at 1-year follow-up. There was also an increase in students seeking medical attention for the FAT (Becker et al., 2010). The authors then compared the AMDBP intervention with an AM-HWI intervention, again both interventions had positive results, with qualitative findings suggesting that AM-HWI seems to be preferred by athletes (Becker et al., 2012). However pre-existing eating pathology may reduce the effectiveness of this type of intervention (Stewart et al., 2014).

A health education intervention designed by Abood and Black, (2000) aimed to increase awareness and skills for developing positive health states and how they enhance performance in female athletes. Results showed that intervention athletes scored lower on drive for thinness and body dissatisfaction and controls had lower self-esteem and nutrition knowledge. BodySense is an educational initiative implemented to increase positive body image in young female athletes based in Ottawa, Canada. Gymnasts and their coaches were targeted with education in this multidimensional, social ecological study. The intervention led to the perception of the gymnasts of feeling reduced pressure about thinness (Buchholz et al., 2008). This suggests that interventions targeting athletes and their coaches can make changes in the sports environment, reducing thinness pressures and ED risk. 
A recent study by Martinsen et al., (2014) examined the effects of a one-year school-based intervention in preventing ED in female athletes in elite Norwegian sports schools. The intervention was based on the social-cognitive framework and aimed to increase self-esteem and motivation. Education on nutrition and adolescent development was also provided to athletes and coaches. Among females, there were no new cases of ED in the intervention schools, while $13 \%$ at the control schools had developed an ED. The study concluded that an intervention program can prevent new cases of ED in adolescent female elite athletes.

Doyle-Lucas \& Davy, (2011) investigated the effects of a nutritional education intervention delivered through a 3 lecture DVD series to adolescent athletes. The intervention program was effective at increasing nutrition knowledge, perceived susceptibility to the FAT, and self-efficacy constructs. The study concluded that to improve overall health and performance, nutrition education should be incorporated into the training regimens of athletes. A similar team-centred prevention program on nutrition, exercise and ED consequences tested by Torres-McGehee et al., (2011) in female athletes had comparable results. There was a significant increase in nutritional and ED knowledge, while drive for thinness and body dissatisfaction decreased in the intervention group. A summary of all prevention interventions is provided in appendix 12.

\subsubsection{N.I. \& U.K.}

In N.I and the UK no formal intervention programs for female athletes with ED have been evaluated. However, the problem has been recognised at the elite level and preventative steps have been taken such as increased employment of performance nutritionists at the sports institute N.I. In the UK athletes are normally referred to treatment through the NHS, unless they have access to private therapists or sports psychologists. UK Sport (2011) has developed an educational booklet for coaches to increase awareness and provide guidance on preventing and treating ED in sport. In N.I, there is no such booklet on guidance available to coaches, a void this study aims to fill, by providing recommendations to coaches in N.I.

\subsection{Screening Interventions}

With current practices less than optimal, there is a need to focus efforts on standardizing screening evaluations specifically for female athletes, to prevent long-term consequences (Javed et al., 
2013) Screening for ED in female athletes differs from screening the general public. Screening tools specifically designed to help distinguish between female athletes with ED and those with behaviours specific to training are required (Knapp, Aerni \& Anderson, 2014). The IOC and the ACSM recommend screening female athletes using athlete-specific screening tools (Nattiv et al., 2007). Despite these recommendations, screening in practice is limited. A study on U.S colleges found that only $6 \%$ were using a validated screening tool (Beals, 2003). Due to the high prevalence rates and increased risk of ED in female athletes it's important that female specific screening tools are utilized. A summary of the evidence for the use of specific screening tools is provided in appendix 13. The FAST, AMDQ and BEDA-Q tools have been validated and show the most promise for use in screening female athletes for clinical ED (Knapp et al., 2014). The FAST can also identify sub-clinical disorders and is currently being updated to align with the DSM-V criteria (Aerni et al., 2014). It may therefore be the most up-to-date tool available. Although screening should usually occur in a clinical setting, coaches could use simple yet effective tools such as the 'SCOFF' questionnaire (Appendix 14) to help in identification (Tury et al., 2010).

\subsection{Pre-participation Examinations \& Symptom Checklists}

A plethora of researchers agree that the pre-participation examination (PPE) is the perfect opportunity to screen athletes for ED and therefore is recommended by many sports organisations such as the ACSM (Javed et al., 2013). However, such an approach is underutilized (Bonci et al., 2008). Over half of U.S colleges using PPE'S use forms missing more than $50 \%$ of the recommended items (Mencias, Noon, \& Hoch, 2012) and fewer than 6\% use standardized screening questionnaires (Beals, 2003). Similarly, in N.I, screening is not a requirement and rarely takes place. With the goal of early identification, the PPE can be used to screen for ED and health issues, however many PPEs vary in content and ability to identify such issues (Thompson \& Sherman, 2010). The IOC has developed a comprehensive PPE screening questionnaire to address these issues and the FAT coalition recommends 12 screening items (Appendix 15) (Mountjoy et al., 2008). An approach used in Canadian Universities is to have a whole section of the PPE dedicated to screening for the FAT (Rumball \& Lebrun, 2005). The adequacy of the PPE in identifying high-risk athletes, particularly adolescents, should not be under-estimated as a preventive approach (Nichols et al., 2006).

A recent approach to screening and identifying female athletes with ED involves the use of a checklist of symptoms and signs of ED (Appendix $5 \& 6$ ). It is a useful first step that can be 
implemented by coaches to detect problems without being intrusive. Several checklists have been produced, including Bonci et al., (2008) and Thompson and Sherman, (2010). Governing bodies such as the NCAA and UK Sport have also produced checklists for coaches to help in identification.

\subsection{Treatment Interventions}

Although coaches will not be involved in the treatment of athletes with ED, an understanding of treatment interventions could help facilitate successful recovery. While the athlete is working with the multi-disciplinary team, they may undergo individual or group therapy. Psychotherapy is a common treatment approach that helps the athlete gain an understanding of the psychological origins of their ED; and learns effective coping strategies (Zach, Machin \& Hoch, 2011). A summary of the various psychotherapies, empirical support and their application to athletes are provided in Appendix 16.

Cognitive-Behavioural Therapy (CBT) incorporates a broad range of approaches and has been found to be the most effective treatment for ED, particularly BN (Shapiro et al., 2007). The goals of CBT in athletes include normalization of eating, reducing dieting, eliminating purging and binge eating, and altering perceptions regarding DE (Juarascio et al., 2010). Although some studies have found positive results with CBT in females (Brownley et al., 2007), other studies have found that CBT is only effective for $50 \%$ of patients (Wilson et al., 2007). Other therapies which have had positive results include Acceptance and Commitment Therapy (Juarascio et al., 2010); Dialectial Behaviour Therapy (Ben-Porath et al., 2009); Enhanced Cognitive Behavioural Therapy (Fairburn et al., 2009), and Dissonance-Based Prevention (Stice et al., 2008). Pharmacological treatment may also be warranted in females with severe menstrual dysfunction, psychological disturbances or osteoporosis. A full discussion of pharmacological interventions is beyond the scope of this study and the reader is directed to De Souza et al. (2014) for a comprehensive review.

\subsection{The Role of the Sports Coach in Eating Disorder Prevention \& Intervention}


This chapter will review the literature to determine the role of the sports coach in ED prevention and intervention in female athletes with ED, based on evidence-based findings. Coaching behaviours suspected in ED development will also be explored along with the current state of knowledge among coaches, with the need for education highlighted.

\subsection{What is the Role of the Coach in Eating Disorder Intervention?}

It has been repeatedly stated in the literature that athletes with ED require treatment from a multidisciplinary healthcare team, representing sports medicine, mental health, nutrition and sports coaching (Mountjoy et al., 2014). As coaches have close contact with athletes they may be considered 'first responders' when it comes to identifying and engaging athletes with ED, therefore they must be able to detect signs and symptoms (Selby \& Reel, 2011). However, due to the complex nature of ED, intervention is most likely to be successful when involving a multidisciplinary team and coaches must call on the support of healthcare professional when necessary (Pantano, 2006). Healthcare professionals often believe that coaches can play a role in precipitating or maintaining ED and as such discourage them from participation in ED treatment due to their conflicts of interest (Joy, 2009). However, with information now available to coaches in this area they are more aware of the seriousness of ED regarding the health of athletes (Sherman, DeHass, Thompson \& Wilfert, 2005).

Coaches can have significant power and influence with athletes, like that of family members (Zimmerman, 1999). In young athletes, coaches have been found to be their strongest source of influence (Francisco et al., 2012). Their power and influence are such that any program related to the identification; management; treatment and prevention of ED most likely will not succeed without their support. By having coaches as part of the team, the co-ordinating healthcare professional can be more aware of their influence, which can provide greater assurance that it has a positive effect (Thompson \& Sherman, 2010).

It has been stated that coaches are in an excellent position to play a role in early identification as they have numerous opportunities to observe athletes under a variety of circumstances. They must know which behaviours are possible symptoms, identify them as such and then know how to respond. However, the goal is not to make coaches into psychologists, rather the coaches' role is to 'recognize and refer' (Sherman \& Thompson, 2010). A study involving 2,894 coaches representing 23 sports in the U.S found that coaches are frequently involved in 
identification and ED symptoms were most often used to identify symptomatic athletes (Sherman et al., 2005). As previously highlighted, coaches could use a predetermined symptom checklist or simple screening tools such as 'SCOFF' to help in identification (Bonci et al., 2008). Coaches have reported using physical, social and performance indicators to identify DE in athletes. Coaches can also monitor athletes' eating attitudes and behaviours with weight loss considered to be a key indicator of ED (Plateau et al., 2013).

If an ED is suspected, initial contact with the athlete should come from an authority figure that they know and trust to ensure the intervention is facilitated with compassion and sensitivity (Bonci et al., 2008). This could be the coach, provided they have a good relationship with the athlete and are comfortable discussing such issues (Thompson \& Sherman, 2010). A close relationship with the athlete can facilitate the identification of DE. However, athlete secrecy, difficulties in communication and coaches' stereotypical beliefs can complicate the identification process (Plateau et al., 2013). The initial conversation should disclose evidence of the disorder and concerns for the athlete's health, followed by referral to a doctor for evaluation and treatment (Bonci et al., 2008). Coaches need to approach the athlete and help them in getting the assistance they need with minimum discomfort or embarrassment. However, the coach must maintain firmness, while explaining expectations and requirements without being critical. Getting the athlete to the medical evaluation is the initial goal (Thompson \& Sherman, 2010). The procedures for managing such a process as recommended by the IOCMC (2005) are in Appendix 17.

It's important that coaches know when to withdraw athletes from sport if ED are suspected in order to maintain their physical and psychological health (Arthur-Cameselle \& Baltzell, 2012). A written contract between the athlete and coach or multi-disciplinary team may be necessary to promote compliance with treatment (Beals, 2004). The athlete may be expected to meet certain health criteria to continue or resume athletic participation (Appendix 18). Although confidentiality is the cornerstone of psychological treatment, many coaches experience it as a stumbling block. Coaches who are genuinely concerned about athletes may become frustrated when unable to receive information about the player's condition (Thompson \& Sherman, 2010). However, most athletes will agree to share medical information with coaches if it focuses on treatment progress (Bonci et al., 2008). As the athlete recovers, reintroduction into sport at a graded pace may be made at the coaches' discretion. Nutritional education integrated into the recovery process can help teach athletes how continued recovery could lead to improvements in performance (Arthur- 
Cameseele \& Baltzell, 2012). Returning to sport can act as a powerful incentive to the athlete to continue treatment (Currie, 2010). The desire to be healthy to perform in sport, frequently facilitates recovery, therefore coaches can help to foster athlete's motivation to recover (ArthurCameselle \& Quatromoni, 2014).

A qualitative study involving coaches found that successful ED prevention strategies adopted by coaches have included educating athletes on healthy eating, maintaining open communication between the coach and athlete and referring to healthcare professionals when necessary (Pantano, 2006). More specific strategies have included emphasising a degree of accountability for athletes' actions, such as keeping a food or menstrual cycle journal, behavioural contracts and enforced exclusion when necessary (Pantano, 2006). These strategies can serve as a model to coaches currently not utilizing an intervention plan and a valuable educational resource for coaches on how to initiate a prevention and treatment program (Appendix 19). Intervention strategies employed by coaches tend to have better outcomes when based on a supportive approach, where coaches are proactive in seeking support and in reducing training at the early stages of an ED (Plateau et al., 2014).

Following treatment, there are limited evidence-based guidelines to assist coaches and the multi-disciplinary team in the assessment of the athlete for clearance and return to play (RTP). Recently two models have been proposed for athletes recovering from ED. A new sport risk assessment and RTP model for RED-S has been developed by Mountjoy et al. (2014). A cumulative risk assessment and decision based RTP model for the FAT (Appendix 20-22) has been developed by De Souza et al. (2014). Although the team physician may have the ultimate say on RTP, the decision is often the product of consultation with the coach (De Souza et al., 2014). These models are the first evidence-based models of their kind to be developed for athletes returning to sport from ED and can be useful in assisting the athlete's team and coach in decisionmaking. Decision-making regarding RTP can be complex, requiring integration and communication between disciplines to facilitate optimal training and competition while managing the athletes' long-term health (Shultz et al., 2013). Recently a new integrated performance health management and coaching model based on UK athletics preparation experience for the London 2012 Olympics (Appendix 23) has been developed by Dijkstra et al. (2014). This model provides a useful example of how a multi-disciplinary team can be formed where coaching is integrated into 
a holistic approach to health management, effective communication and decision-making for athletes returning to sport following illness.

\subsection{Are Coaching Behaviours a Risk Factor for Eating Disorders?}

Coaches are in a unique position to denounce unhealthy attitudes and behaviours that may trigger ED. However, they also juggle a combination of role demands and conflicts that are not always consistent with making decisions in the best interest of an athlete's health (Bonci et al., 2008). Inappropriate coaching behaviour has been found to be an important risk factor for ED development in athletes, which could precipitate or exacerbate DE attitudes and behaviours in susceptible athletes (Sundgot-Borgen \& Torstveit, 2010). Pressure from coaches regarding eating habits, weight, physical appearance and performance appear to be a risk factor for ED development in female athletes (Toro et al., 2005). Coaches can have unrealistic expectations about weight and body image, which adds pressure on athletes to conform to certain weight or image driven standards. Perceptions that coaches hold about ED also present a set of risk factors that may increase the likelihood of female athletes developing maladaptive eating patterns (Scoffier, Maiano, \& d'Arripe-Longueville, 2010). Such beliefs and behaviour can have disastrous consequences for athletes. For example, team GB triathlete Hollie Avil retired from elite sport after battling an ED she says was triggered by a coach's comments regarding her weight (BBC, 2012).

Coaches' comments regarding weight could raise the risk for ED (Gomes et al. 2011). It's been found that ED are more likely to occur in female athletes who diet unsupervised after receiving negative comments regarding their weight from coaches' (Sundgot-Borgen, 1994). Gymnasts, who receive negative comments from coaches' regarding body size and weight, report more DE (Kerr et al., 2006). Comparably, De Bruin et al., (2007) found that the eating patterns of elite female gymnasts were more related to perceived weight pressures from coaches than body image issues. Therefore, it's important that coaches are aware of their influence on female athletes and the need to avoid negative comments which may precipitate an ED.

Many high-level coaches have encountered disturbed eating among their athletes, and some of their coaching attitudes and behaviours may inadvertently increase the risk for such disturbances (Heffner et al., 2003). The sport environment has a unique impact on athletes' ED development. In particular, negative comments by coaches, modelling of ED 
behaviours by other athletes, and sport performance pressure all contribute to eating pathology (Arthur-Cameselle \& Quatromoni, 2011). A culture in sport which promotes thinness can be reinforced by coaches and this prevailing discourse can precipitate ED's through on-going surveillance and self-discipline (Jones et al., 2005). A study examining the impact of coaching style on vulnerability of ED found that a performance related, and body weight preoccupied coaching style led to increased dieting and body image anxiety. Conversely a supportive and caring coaching style was found to reduce risk of ED (Biesecker \& Martz, 1999).

Athletes' eating psychopathology can be predicted by perceived levels of interpersonal conflict with coaches, suggesting that conflict within the coach-athlete relationship is a potential risk factor for ED among athletes. Therefore, coaches must be aware of its potentially toxic role (Shanmugam, Jowett \& Meyer, 2014). A relationship between conflict with coaches and ED in female athletes has also been found to be associated with impaired performance (Tamminen et al., 2013). However a low prevalence of ED among student-athletes who reported that they did not receive any pressure from coaches to lose weight has been found, suggesting that healthy relationships between athletes and coaches may lessen the risk (Van Zyl et al., 2012). There is a need to re-interpret the traditional coach-athlete relationship, to ensure it is a positive one and contributes to preventing harmful eating behaviours (Jones et al., 2005). Sports coaches can contribute to reducing ED risk by providing a supportive environment for athletes and reducing levels of criticism and bullying regarding weight (Currie, 2010). Improvement of the coach-athlete relationship could also lead to enhanced performance. Psychological factors such as this can improve performance and help determine the realization of potential in athletes' (Burton \& Raedeke, 2008).

Although dieting to lose weight and using unhealthy methods are ED symptoms (APA, 2013) many athletes are dieting to lose weight in response to criticism from coaches' (Kerr et al., 2006). Excessive exercise is a common ED characteristic (APA, 2013) which may be seen as a good athlete trait and a desired behaviour, which is encouraged and rewarded by coaches' (Thompson \& Sherman, 2010). Another area in which coaches need more information is in the area of menstrual functioning and its relationship with $E D$, as many coaches still view amenorrhea as normal. Experiential training in talking with sportswomen about menstrual issues might be helpful for some coaches (Sherman et al., 2005). Coaches must use their power and influence to deemphasize weight and focus on nutrition to help prevent rather than promote ED. Coaches should also not be involved in weighing athletes and group weigh-ins should be avoided, unless 
they are assisted by health professionals (Thompson \& Sherman, 2010). Coaches can also play a role in reducing the problems associated with competitive thinness and behavioural contagion in a team setting by discouraging 'fat talk' regarding body dissatisfaction (Stice et al., 2003). When hearing such talk coaches may need to discourage it by responding that such talk is negative, unhealthy and has no place in sport (Ousley et al., 2008).

\section{3 Is There a Lack of Knowledge \& Education for Coaches?}

Sports coaches play an important role in the identification, management and treatment of athletes with ED (Sundgot-Borgen, 1994). Similarly, their importance regarding prevention cannot be overstated. It is unlikely that any prevention program or initiative regarding athletes can be successful without the support, endorsement and participation of coaches (Thompson \& Sherman, 2010). However, some studies have indicated that coaches have limited confidence and knowledge on nutrition and ED (Sossin et al., 1997) and require better training and education on ED (Sherman et al., 2005). Coaches tend to use appearance and performance as a basis for weight recommendations, rather than being attentive to unhealthy weight control behaviours (Harris, 2000).

There is a need for coaches to achieve a greater knowledge of ED in all domains through comprehensive education. However educational programs about ED are not often endorsed by sports organisations for coaches and communication is poor regarding their availability (Turk et al., 1999) Sports organisations should be encouraged to develop and implement ED policies and continuing education for coaches on the prevention of ED among athletes is strongly recommended (Vaughan, King \& Cottrell, 2004). Education is necessary for improving coaches' knowledge and confidence; to reduce risk of ED (Torres-McGehee et al., 2011). When sports coaches have high levels of knowledge of ED, it correlates with greater confidence in dealing with them. Years of coaching and gender do not seem to affect knowledge and confidence, suggesting that obtaining knowledge through education is crucial to increasing coaches' confidence in dealing with ED's among athletes (Govero \& Bushman, 2003).

It has also been found that coaches' knowledge of the FAT is limited and barriers to FAT screening and education are coaches' insufficient time, knowledge, and educational resources. Therefore, providing coaches with FAT screening/education training may increase knowledge and 
decrease FAT risk among athletes (Brown, Wengreen \& Beals, 2014). In one study only $8 \%$ of sports coaches were able to identify all three components of the FAT suggesting that a heightened level of awareness and education in the proper treatment of the FAT is needed (Troy, Hoch \& Stavrakos et al., 2006). Education interventions for coaches may help mitigate the health consequences for athletes related to possible differential prevention and detection of the comorbidities of the FAT (Kroshus et al., 2014). Coaches with more knowledge about the FAT are more likely to know how to identify and treat a female athlete with symptoms of the FAT, employ preventative strategies and screen for the triad. These coaches are also more likely to co-ordinate a multi-disciplinary team and assessment (Pantano, 2006).

A recent qualitative study with elite coaches in Sweden concluded that coaches have insufficient capacity to identify ED and conduct early intervention, resulting in delayed treatment. Most coaches cited difficulty in identifying ED symptoms and several barriers in approaching athletes, such as athlete denial and lack of easily accessible resources for treatment referral on both national and club level (Nowicka et al., 2013). Another qualitative study involving interviews with athletes who had recovered from ED, reached a similar conclusion that there is a strong need for further education for coaches in identifying and treating athletes with ED (Arthur-Cameselle \& Baltzell, 2012). For the appropriate identifications and referrals to be made, coaches require a full working knowledge of ED (Bratland-Sandra \& Sundgot-Borgen, 2013). Increasing knowledge can enable coaches to play an active role in providing athletes information and mechanisms to help prevent ED (Frideres \& Palao, 2008).

Coaches' decision making can be complicated by their lack of formal training in sports science disciplines that affect health. When demands of coaching combine with inadequate education, coaches are more vulnerable to; careless comments, misinformation and inappropriate actions which can jeopardize athlete's health (Bonci et al., 2008). Coaches have reported facing challenges in persuading athletes to seek treatment and are often frustrated by the lack of available support, highlighting the importance of providing resources and support services where coaches can seek advice. Coach-education packages should reinforce the importance of their role in identification and intervention (Plateau et al., 2014). The more educated coaches are the more likely they are to promote healthy eating and weight habits and interact positively with symptomatic athletes. Only through mandatory, formal education programs can coaches promote healthy behaviours that have the potential to counteract development of ED (Bonci et al., 2008). Increased knowledge among sports coaches of early symptoms indicating ED is therefore crucial 
in prevention (Melin et al., 2014). Coaches can make an important contribution to preventing ED's and specific training or assistance may be required in order to enable coaches to conduct effective preventive activities (Yager \& O’Dea, 2005).

Coaches should be targeted for education about the risk factors of ED as they are potential agents for early detection of ED. They also should be alerted to deterioration in sport performance and signs of dehydration or being underweight in athletes may indicate the need for medical intervention (El Ghoch et al., 2013). Sports organisations, governing bodies and professionals who work with athletes have a responsibility to implement good preventative practices. Sport's governing bodies can be impactful regarding prevention of ED. We cannot expect coaches to take seriously the harm of ED if their governing bodies do not take a strong proactive approach. This type of commitment must be apparent in their official communications and reflected in the funding provided for prevention programs and training for coaches (Thompson \& Sherman, 2010). For example, UK Sport (2011) has produced an educational booklet for coaches to help raise awareness of ED in sport.

\subsection{Are Coach Education Interventions Effective?}

Some recent studies have attempted to ascertain if coach education interventions are effective in preventing ED. A recent study by Martinsen et al. (2014) investigated a one-year intervention targeting coaches in elite Norwegian sports schools, which provided education and strategies regarding healthy nutrition, eating behavior, and ED intervention. Intervention coaches had higher scores on total knowledge, weight-regulation, and ED (including recognition and management) than controls. There were no new cases of ED found among females in the intervention schools. This randomized control trial specifically targeting sports coaches was the first of its kind and shows how providing education to coaches can help prevent ED in adolescent female athletes.

An earlier study by Whisenhunt et al., (2008) targeted coaches as potential change agents by training them to recognize the symptoms of ED and reduce the pressures for thinness. Coaches received information regarding negative coaching behaviours, the symptoms and management of ED's. Eight months following the workshop, the coaches were assessed, and results indicated that the intervention was successful in producing behavior changes. However, the intervention was less successful in producing long-term change in knowledge about ED's. 
These findings imply that interventions can be successfully implemented with coaches, but their overall effectiveness must be enhanced in order to have a significant long-term impact.

\subsection{Conclusion}

Despite the positive benefits of sports participation, female athletes appear to be at increased risk of developing clinical ED such as AN, BN, OFSED, and BED. Female athletes are also at risk of developing sub-clinical eating conditions such as AA, the FAT and RED-S. These conditions can have serious mental and physical health consequences, such as menstrual dysfunction and osteoporosis, therefore early identification is crucial to prevent long-term consequences. While genetic and sociocultural risk-factors play a role in ED development, risk-factors unique to the sports environment need to be considered in female athletes, such as weight and body image pressures, competitive thinness and revealing uniforms. Despite heterogeneity in prevalence studies, findings suggest that female athletes are at higher risk than male athletes and nonathletes, and those in elite level sports or sports categorised as lean, aesthetic, endurance and weight-class are at increased risk for ED. Variances in findings are often due to differences in study methodology, classification issues and the use of different measurement instruments. Therefore, it can be difficult to draw accurate conclusions about prevalence data. Future research should address these limitations to provide more accurate data regarding the scope of the problem in female athletes.

Despite a dearth of studies on EBI for ED in sport, findings suggest that Primary prevention programs based on educating athletes such as ATHENA show most promise in prevention. Secondary prevention should focus on early identification using athlete-specific screening tools, with the FAST, AMDQ and BEDA-Q showing the most promise. Symptom checklists and preparticipation examinations can also assist coaches in early identification. Psychotherapy interventions such as CBT have the most positive results for treatment. The paucity of prevention and educational programs designed to decrease the incidence of ED's in sport is alarming, given the fact they are more prevalent in the sport environment. More long-term controlled prevention studies are needed to determine which interventions are most effective with female athletes. Information alone is not likely to produce prevention of ED's; however, education is still needed by coaches, governing bodies, athletes and parents. 
Sports coaches play a critical role in the early identification, referral, management and prevention of ED in female athletes. However, findings suggest that many coaches lack knowledge about ED and require education to be able to intervene successfully with female athletes with ED. Inappropriate coaching behaviours have also been found to act as an additional risk-factor for ED. Coaches must be aware of these behaviours and take steps to avoid them. Coach education interventions have been found to reduce these behaviours, increase knowledge and reduce ED in the short-term. However further long-term studies are needed to ascertain their long-term effectiveness. The following recommendations for sports coaches are provided as a guide to assist them in successful intervention, management and return to play of female athletes with ED based on the findings in the literature. These recommendations should be made available to coaches in N.I. as there is currently no evidence-based intervention guide available.

\subsection{Recommendations for Sports Coaches}

- Increase knowledge \& awareness of ED through education.

- Gain a full understanding of the relationship between weight, performance and adequate nutrition through education.

- Place emphasis on healthy eating, nutrition \& exercise to athletes, opposed to focusing on weight \& appearance.

- Use their power and influence with athletes to a positive effect during ED intervention.

- Avoid inappropriate language, criticism and comments regarding weight or dieting.

- Avoid singling out players due to their body shape or weight.

- Avoid unrealistic expectations about weight and body image, which adds pressure on athletes.

- Dispel myths that thinness will always improve performance.

- De-emphasize weight and eliminate weigh-ins unless supervised by health professionals.

- Discourage 'fat talk' regarding body dissatisfaction and competitive thinness by stating that such talk is negative, unhealthy and has no place in sport.

- Show empathy and be sensitive when approaching symptomatic athletes.

- Emphasise a degree of accountability for athlete's actions, such as keeping a food or menstrual cycle journal or behavioural contracts.

- Engage in experiential training in talking with sportswomen about menstrual issues. 
- Use a predetermined symptom checklists and evidence-based screening tools such as the SCOFF questionnaire to help in identification of ED's.

- When an ED is suspected, approach athlete early, directly and confidentially, not in the presence of other athletes. Gain athletes consent for referral to healthcare professionals and for evidence-based treatments such as psychotherapy.

- Use a supportive approach, where coaches are proactive in seeking support and in reducing training at the early stages of an eating problem.

- Ensure healthy coach-athlete relationships, with open communication and free from conflicts and pressure.

- Consider removing athlete from training/competition if health risks are evident.

- When applicable, Initiate the formation of a multi-disciplinary team to support the athlete who has an ED, with coaches integrated into a holistic approach to health management.

- A written contract between the athlete and coach or multi-disciplinary team may be necessary to promote compliance with treatment.

- During recovery, coaches can provide nutritional education and help foster the athlete's motivation to recover and reach higher levels of performance.

- Use evidence-based risk assessment and return to play models for assessment and clearance following treatment.

\subsection{Limitations}

This study has adopted an entirely theoretical approach, where secondary published literature on ED in female athletes and EBI has been examined. Adopting quantitative methods, such as examining statistical data and trends may help identify prevalence's and risk factors for ED in female athletes more accurately. Qualitative methods involving personal data collection such as interviews with athletes and coaches in N.I would help identify their views and may provide different implications. There are also several limitations relating to bias. As the review focused on studies with positive findings, it may not be representative of all studies conducted and may have publication bias. There may also be location bias as some studies published in journals which are not indexed in bibliographic databases may have not been identified by electronic searches. There may also be language bias as the study was restricted to English language papers, so studies in local language journals may have been missed. Finally, as only full-text studies were included, some recent studies available in abstract only format may have been missed. 


\section{References}

Aardoom, J.J., Dingemans, A.E., Slof Op't Landt, Margarita CT \& Van Furth, E.F. 2012, "Norms and discriminative validity of the Eating Disorder Examination Questionnaire (EDE-Q)", Eating Behaviors, vol. 13, no. 4, pp. 305-309.

Abood, D.A. \& Black, D.R. 2000, "Health education prevention for eating disorders among college female athletes", American Journal of Health Behavior, vol. 24, no. 3, pp. 209-219.

Ackerman, K.E. \& Misra, M. 2011, "Bone health and the female athlete triad in adolescent athletes", The Physician and sportsmedicine, vol. 39, no. 1, pp. 131-141.

Ackland, T.R., Lohman, T.G., Sundgot-Borgen, J., Maughan, R.J., Meyer, N.L., Stewart, A.D. \& Muller, W. 2012, "Current status of body composition assessment in sport: review and position statement on behalf of the ad hoc research working group on body composition health and performance, under the auspices of the I.O.C. Medical Commission", Sports medicine (Auckland, N.Z.), vol. 42, no. 3, pp. 227-249.

American Psychiatric Association 2013, The Diagnostic and Statistical Manual of Mental Disorders: DSM 5, bookpointUS.

Annus, A.M., Smith, G.T., Fischer, S., Hendricks, M. \& Williams, S.F. 2007, "Associations among family-of-origin food-related experiences, expectancies, and disordered eating", The International journal of eating disorders, vol. 40, no. 2, pp. 179-186.

Arthur-Cameselle, J.N. \& Baltzell, A. 2012, "Learning from collegiate athletes who have recovered from eating disorders: Advice to coaches, parents, and other athletes with eating disorders", Journal of Applied Sport Psychology, vol. 24, no. 1, pp. 1-9.

Arthur-Cameselle, J.N. \& Quatromoni, P.A. 2014, "Eating Disorders in Collegiate Female Athletes: Factors That Assist Recovery", Eating disorders, vol. 22, no. 1, pp. 50-61.

Arthur-Cameselle, J.N. \& Quatromoni, P.A. 2010, "Factors related to the onset of eating disorders reported by female collegiate athletes", Sport Psychologist, vol. 25, pp. 1-17. 
Bachner-Melman, R., Zohar, A.H., Ebstein, R.P., Elizur, Y. \& Constantini, N. 2006, "How anorexiclike are the symptom and personality profiles of aesthetic athletes?", Medicine and science in sports and exercise, vol. 38, no. 4, pp. 628-636.

Baer, R.A. 2005, Mindfulness-based treatment approaches: Clinician's guide to evidence base and applications, Academic Press.

Barrack, M.T., Gibbs, J.C., De Souza, M.J., Williams, N.I., Nichols, J.F., Rauh, M.J. \& Nattiv, A. 2014, "Higher incidence of bone stress injuries with increasing female athlete triad-related risk factors: a prospective multisite study of exercising girls and women", The American Journal of Sports Medicine, vol. 42, no. 4, pp. 949-958.

Barrack, M.T., Rauh, M.J., Barkai, H.S. \& Nichols, J.F. 2008, "Dietary restraint and low bone mass in female adolescent endurance runners", The American Journal of Clinical Nutrition, vol. 87, no. 1 , pp. 36-43.

Barrack, M.T., Rauh, M.J. \& Nichols, J.F. 2008, "Prevalence of and traits associated with low BMD among female adolescent runners", Medicine and science in sports and exercise, vol. 40, no. 12, pp. 2015-2021.

Beals, K.A. 2004, Disordered eating among athletes: a comprehensive guide for health professionals. Human Kinetics.

Beals, K.A. 2003, "Eating disorder and menstrual dysfunction screening, education, and treatment programs", The Physician and sportsmedicine, vol. 31, no. 7, pp. 33-38.

Becker, A., Fay, K., Wonderlich, S., Mitchell, J., Zwaan, M.d. \& Steiger, H. 2006, "Sociocultural issues and eating disorders.", Annual Review of Eating Disorders: Part 2, , pp. 35-63.

Becker, C.B., McDaniel, L., Bull, S., Powell, M. \& McIntyre, K. 2012, "Can we reduce eating disorder risk factors in female college athletes? A randomized exploratory investigation of two peer-led interventions", Body image, vol. 9, no. 1, pp. 31-42.

Becker, C.B., Wilson, C., Williams, A., Kelly, M., McDaniel, L. \& Elmquist, J. 2010, "Peer-facilitated cognitive dissonance versus healthy weight eating disorders prevention: A randomized comparison", Body image, vol. 7, no. 4, pp. 280-288. 
Ben-Porath, D.D., Wisniewski, L. \& Warren, M. 2009, "Differential treatment response for eating disordered patients with and without a comorbid borderline personality diagnosis using a dialectical behavior therapy (DBT)-informed approach", Eating disorders, vol. 17, no. 3, pp. 225-241.

Berg, K.C., Peterson, C.B., Frazier, P. \& Crow, S.J. 2012, "Psychometric evaluation of the eating disorder examination and eating disorder examination-questionnaire: A systematic review of the literature", International Journal of Eating Disorders, vol. 45, no. 3, pp. 428-438.

Biesecker, A.C. \& Martz, D.M. 1999, "Impact of coaching style on vulnerability for eating disorders: An analog study", Eating Disorders, vol. 7, no. 3, pp. 235-244.

Birmingham, C.L., Su, J., Hlynsky, J.A., Goldner, E.M. \& Gao, M. 2005, "The mortality rate from anorexia nervosa", The International journal of eating disorders, vol. 38, no. 2, pp. 143-146.

Black, D.R., Larkin, L.J., Coster, D.C., Leverenz, L.J. \& Abood, D.A. 2003, "Physiologic Screening Test for Eating Disorders/Disordered Eating Among Female Collegiate Athletes", Journal of athletic training, vol. 38, no. 4, pp. 286-297.

Boland, A., Cherry, M.G. \& Dickson, R. 2013, Doing a Systematic Review: A Student's Guide, Sage.

Bonci, C.M., Bonci, L.J., Granger, L.R., Johnson, C.L., Malina, R.M., Milne, L.W., Ryan, R.R. \& Vanderbunt, E.M. 2008, "National athletic trainers' association position statement: preventing, detecting, and managing disordered eating in athletes", Journal of athletic training, vol. 43, no. 1 , pp. 80-108.

Bratland-Sanda, S. \& Sundgot-Borgen, J. 2013, "Eating disorders in athletes: overview of prevalence, risk factors and recommendations for prevention and treatment", European journal of sport science, vol. 13, no. 5, pp. 499-508.

Brewerton, T. 2005, "Psychological trauma and eating disorders", AED Review of Eating Disorders, Part, vol. 1, pp. 137-154. 
Brown, K.N., Wengreen, H.J. \& Beals, K.A. 2014, "Knowledge of the female athlete Triad, and prevalence of Triad risk factors among female high school athletes and their coaches", Journal of pediatric and adolescent gynecology, vol. 27, no. 5, pp. 278-282.

Brownley, K.A., Berkman, N.D., Sedway, J.A., Lohr, K.N. \& Bulik, C.M. 2007, "Binge eating disorder treatment: a systematic review of randomized controlled trials", International Journal of Eating Disorders, vol. 40, no. 4, pp. 337-348.

Buchholz, A., Mack, H., McVey, G., Feder, S. \& Barrowman, N. 2008, "Bodysense: An evaluation of a positive body image intervention on sport climate for female athletes", Eating disorders, vol. 16 , no. 4, pp. 308-321.

Bulik, C.M. \& Allison, D.B. 2002, "Constitutional thinness and resistance to obesity", Eating disorders and obesity: A comprehensive handbook, , pp. 22-25.

Bulik, C.M., Sullivan, P.F. \& Kendler, K.S. 1998, "Heritability of binge-eating and broadly defined bulimia nervosa", Biological psychiatry, vol. 44, no. 12, pp. 1210-1218.

Burton, D. \& Raedeke, T.D. 2008, "Sport psychology for coaches", International Journal of Sports Science and Coaching, vol. 3, no. 2, pp. 291-292.

Call, C., Walsh, B.T. \& Attia, E. 2013, "From DSM-IV to DSM-5: changes to eating disorder diagnoses", Current opinion in psychiatry, vol. 26, no. 6, pp. 532-536.

Cash, T.F., Fleming, E.C., Alindogan, J., Steadman, L. \& Whitehead, A. 2002, "Beyond body image as a trait: the development and validation of the Body Image States Scale", Eating disorders, vol. 10, no. 2, pp. 103-113.

Coelho, Gabriela Morgado de Oliveira, Farias, Maria Lucia Fleiuss de, Mendonça, Laura Maria Carvalho de, Mello, D.B.d., Lanzillotti, H.S., Ribeiro, B.G. \& Soares, E.d.A. 2013, "The prevalence of disordered eating and possible health consequences in adolescent female tennis players from Rio de Janeiro, Brazil", Appetite, vol. 64, pp. 39-47.

Coelho, G.M., Gomes, A.I., Ribeiro, B.G. \& Soares Ede, A. 2014, "Prevention of eating disorders in female athletes", Open access journal of sports medicine, vol. 5, pp. 105-113. 
Coelho, G.M., Soares Ede, A. \& Ribeiro, B.G. 2010, "Are female athletes at increased risk for disordered eating and its complications?", Appetite, vol. 55, no. 3, pp. 379-387.

Crandall, C.S. 1988, "Social contagion of binge eating", Journal of personality and social psychology, vol. 55, no. 4, pp. 588-598.

Currie, A. 2010, "Sport and eating disorders - understanding and managing the risks", Asian journal of sports medicine, vol. 1, no. 2, pp. 63-68.

da Costa, N.F., Schtscherbyna, A., Soares, E.A. \& Ribeiro, B.G. 2013, "Disordered eating among adolescent female swimmers: dietary, biochemical, and body composition factors", Nutrition (Burbank, Los Angeles County, Calif.), vol. 29, no. 1, pp. 172-177.

De Bruin, A., Bakker, F.C. \& Oudejans, R.R. 2009, "Achievement goal theory and disordered eating: Relationships of disordered eating with goal orientations and motivational climate in female gymnasts and dancers", Psychology of Sport and Exercise, vol. 10, no. 1, pp. 72-79.

De Bruin, A., Oudejans, R.R. \& Bakker, F.C. 2007, "Dieting and body image in aesthetic sports: A comparison of Dutch female gymnasts and non-aesthetic sport participants", Psychology of Sport and Exercise, vol. 8, no. 4, pp. 507-520.

De Souza, M.J., Williams, N.I., Nattiv, A., Joy, E., Misra, M., Loucks, A.B., Matheson, G., Olmsted, M.P., Barrack, M., Mallinson, R.J., Gibbs, J.C., Goolsby, M., Nichols, J.F., Drinkwater, B., Sanborn, C., Agostini, R., Otis, C.L., Johnson, M.D., Hoch, A.Z., Alleyne, J.M., Wadsworth, L.T., Koehler, K., VanHeest, J., Harvey, P., Kelly, A.K., Fredericson, M., Brooks, G.A., O'Donnell, E., Callahan, L.R., Putukian, M., Costello, L., Hecht, S., Rauh, M.J. \& McComb, J. 2014, "Misunderstanding the female athlete triad: refuting the IOC consensus statement on Relative Energy Deficiency in Sport (RED-S)", British journal of sports medicine, vol. 48, no. 20, pp. 1461-1465.

DiBartolo, P.M. \& Shaffer, C. 2002, "A comparison of female college athletes and nonathletes: Eating disorder symptomatology and psychological well-being", Journal of Sport and Exercise Psychology, vol. 24, no. 1, pp. 33-41. 
Dijkstra, H.P., Pollock, N., Chakraverty, R. \& Alonso, J.M. 2014, "Managing the health of the elite athlete: a new integrated performance health management and coaching model", British journal of sports medicine, vol. 48, no. 7, pp. 523-531.

Doninger, G.L., Enders, C.K. \& Burnett, K.F. 2005, "Validity evidence for Eating Attitudes Test scores in a sample of female college athletes", Measurement in physical education and exercise science, vol. 9, no. 1, pp. 35-49.

Doyle-Lucas, A.F. \& Davy, B.M. 2011, "Development and evaluation of an educational intervention program for pre-professional adolescent ballet dancers: nutrition for optimal performance", Journal of Dance Medicine \& Science, vol. 15, no. 2, pp. 65-75.

Duffy, A. 2008, "Perfectionism, perfectionistic self-presentation, body comparisons, and disordered eating in Women's Artistic Gymnastics.", .

El Ghoch, M., Soave, F., Calugi, S. \& Dalle Grave, R. 2013, "Eating disorders, physical fitness and sport performance: a systematic review", Nutrients, vol. 5, no. 12, pp. 5140-5160.

Elliot, D.L., Goldberg, L., Moe, E.L., Defrancesco, C.A., Durham, M.B. \& Hix-Small, H. 2004, "Preventing substance use and disordered eating: initial outcomes of the ATHENA (athletes targeting healthy exercise and nutrition alternatives) program", Archives of Pediatrics \& Adolescent Medicine, vol. 158, no. 11, pp. 1043-1049.

Elliot, D.L., Goldberg, L., Moe, E.L., Defrancesco, C.A., Durham, M.B., McGinnis, W. \& Lockwood, C. 2008, "Long-term Outcomes of the ATHENA (Athletes Targeting Healthy Exercise \& Nutrition Alternatives) Program for Female High School Athletes", Journal of Alcohol and Drug Education, vol. 52, no. 2, pp. 73-92.

Elliot, D.L., Moe, E.L., Goldberg, L., DeFrancesco, C.A., Durham, M.B. \& Hix-Small, H. 2006, "Definition and outcome of a curriculum to prevent disordered eating and body-shaping drug use", The Journal of school health, vol. 76, no. 2, pp. 67-73.

Engel, S.G., Johnson, C., Powers, P.S., Crosby, R.D., Wonderlich, S.A., Wittrock, D.A. \& Mitchell, J.E. 2003, "Predictors of disordered eating in a sample of elite Division I college athletes", Eating Behaviors, vol. 4, no. 4, pp. 333-343. 
Fairburn, C.G., Peveler, R.C., Jones, R., Hope, R. \& Doll, H.A. 1993, "Predictors of 12-month outcome in bulimia nervosa and the influence of attitudes to shape and weight.", Journal of consulting and clinical psychology, vol. 61, no. 4, pp. 696.

Fairburn, C., Cooper, Z., Doll, H., O'Connor, M., Bohn, K., Hawker, D., Wales, J. \& Palmer, R. 2009, "Transdiagnostic cognitive-behavioral therapy for patients with eating disorders: a twosite trial with 60-week follow-up", American Journal of Psychiatry, vol. 166, no. 3, pp. 311319.

Fasting, K., Brackenridge, C. \& Sundgot-Borgen, J. 2004, "Prevalence of Sexual Harassment among Norwegian Female Elite Athletes Inrelation to Sport Type", International Review for the Sociology of Sport, vol. 39, no. 4, pp. 373-386.

Forsberg, S. \& Lock, J. 2006, "The relationship between perfectionism, eating disorders and athletes: a review", Minerva pediatrica, vol. 58, no. 6, pp. 525-536.

Francisco, R., Narciso, I. \& Alarcao, M. 2013, "Individual and relational risk factors for the development of eating disorders in adolescent aesthetic athletes and general adolescents", Eating and weight disorders : EWD, vol. 18, no. 4, pp. 403-411.

Garcia-Campayo, J., Sanz-Carrillo, C., Ibáñez, J., Lou, S., Solano, V. \& Alda, M. 2005, "Validation of the Spanish version of the SCOFF questionnaire for the screening of eating disorders in primary care", Journal of psychosomatic research, vol. 59, no. 2, pp. 51-55.

Garner, D.M. 2004, EDI 3: Eating Disorder Inventory-3: Professional Manual, Psychological Assessment Resources.

Garner, D.M. \& Garfinkel, P.E. 1979, "The Eating Attitudes Test: An index of the symptoms of anorexia nervosa", Psychological medicine, vol. 9, no. 02, pp. 273-279.

Garner, D.M. \& Olmsted, M.P. 1984, Manual for eating disorder inventory (EDI), Psychological Assessment Resources, Incorporated.

Garner, D.M., Olmsted, M.P., Bohr, Y. \& Garfinkel, P.E. 1982, "The eating attitudes test: psychometric features and clinical correlates", Psychological medicine, vol. 12, no. 04, pp. 871-878. 
Gibbs, J.C., Williams, N.I., Scheid, J.L., Toombs, R.J. \& De Souza, M.J. 2011, "The association of a high drive for thinness with energy deficiency and severe menstrual disturbances: confirmation in a large population of exercising women", International Journal of Sport Nutrition andExercise Metabolism, vol. 21, no. 4, pp. 280.

Gibbs, J.C., Williams, N.I. \& De Souza, M.J. 2013, "Prevalence of individual and combined components of the female athlete triad", Medicine and science in sports and exercise, vol. 45, no. 5, pp. 985-996.

Gomes, A.R., Martins, C. \& Silva, L. 2011, "Eating disordered behaviours in Portuguese athletes: The influence of personal, sport, and psychological variables", European Eating Disorders Review, vol. 19, no. 3, pp. 190-200.

Govero, C. \& Bushman, B. 2003, "Collegiate cross country coaches' knowledge of eating disorders", Women in sport and physical activity journal, vol. 12, no. 1, pp. 53-65.

Greenleaf, C. 2002, "Athletic body image: exploratory interviews with former competitive female athlete", Women in sport \& physical activity journal, vol. 11, no. 1, pp. 63.

Greydanus, D.E., Omar, H. \& Pratt, H.D. 2010, "The adolescent female athlete: current concepts and conundrums", Pediatric clinics of North America, vol. 57, no. 3, pp. 697-718.

Gulliver, A., Griffiths, K.M., Mackinnon, A., Batterham, P.J. \& Stanimirovic, R. 2014, "The mental health of Australian elite athletes", Journal of science and medicine in sport / Sports Medicine Australia, .

Hagmar, M., Hirschberg, A.L., Berglund, L. \& Berglund, B. 2008, "Special attention to the weightcontrol strategies employed by Olympic athletes striving for leanness is required", Clinical journal of sport medicine : official journal of the Canadian Academy of Sport Medicine, vol. 18, no. 1 , pp. 5-9.

Hausenblas, H.A. \& McNally, K.D. 2004, "Eating disorder prevalence and symptoms for track and field athletes and nonathletes", Journal of Applied Sport Psychology, vol. 16, no. 3, pp. 274286. 
Heffner, J.L., Ogles, B.M., Gold, E., Marsden, K. \& Johnson, M. 2003, "Nutrition and eating in female college athletes: A survey of coaches", Eating Disorders, vol. 11, no. 3, pp. 209-220.

Heffner, M., Sperry, J., Eifert, G.H. \& Detweiler, M. 2002, "Acceptance and commitment therapy in the treatment of an adolescent female with anorexia nervosa: A case example", Cognitive and Behavioral Practice, vol. 9, no. 3, pp. 232-236.

Herbrich, L., Pfeiffer, E., Lehmkuhl, U. \& Schneider, N. 2011, "Anorexia athletica in preprofessional ballet dancers", Journal of sports sciences, vol. 29, no. 11, pp. 1115-1123.

Hill, L.S., Reid, F., Morgan, J.F. \& Lacey, J.H. 2010, "SCOFF, the development of an eating disorder screening questionnaire", International Journal of Eating Disorders, vol. 43, no. 4, pp. 344-351.

Hoch, A.Z., Pajewski, N.M., Moraski, L., Carrera, G.F., Wilson, C.R., Hoffmann, R.G., Schimke, J.E. \& Gutterman, D.D. 2009, "Prevalence of the female athlete triad in high school athletes and sedentary students", Clinical journal of sport medicine : official journal of the Canadian Academy of Sport Medicine, vol. 19, no. 5, pp. 421-428.

Hoch, A.Z., Papanek, P., Szabo, A., Widlansky, M.E., Schimke, J.E. \& Gutterman, D.D. 2011, "Association between the female athlete triad and endothelial dysfunction in dancers", Clinical journal of sport medicine : official journal of the Canadian Academy of Sport Medicine, vol. 21, no. 2, pp. 119-125.

Hoch, A.Z., Stavrakos, J.E. \& Schimke, J.E. 2007, "Prevalence of female athlete triad characteristics in a club triathlon team", Archives of Physical Medicine and Rehabilitation, vol. 88, no. 5, pp. 681-682.

Hudson, J.I., Hiripi, E., Pope, H.G.,Jr \& Kessler, R.C. 2007, "The prevalence and correlates of eating disorders in the National Comorbidity Survey Replication", Biological psychiatry, vol. 61 , no. 3, pp. 348-358.

Hulley, A., Currie, A., Njenga, F. \& Hill, A. 2007, "Eating disorders in elite female distance runners: Effects of nationality and running environment", Psychology of Sport and Exercise, vol. 8, no. 4, pp. 521-533. 
Hulley, A.J. \& Hill, A.J. 2001, "Eating disorders and health in elite women distance runners", The International journal of eating disorders, vol. 30, no. 3, pp. 312-317.

Jacobi, C., Hayward, C., de Zwaan, M., Kraemer, H.C. \& Agras, W.S. 2004, "Coming to terms with risk factors for eating disorders: application of risk terminology and suggestions for a general taxonomy.", Psychological bulletin, vol. 130, no. 1, pp. 19.

Jankauskiene, R. \& Pajaujiene, S. 2012, "Disordered eating attitudes and body shame among athletes, exercisers and sedentary female college students", The Journal of sports medicine and physical fitness, vol. 52, no. 1, pp. 92-101.

Javed, A., Tebben, P.J., Fischer, P.R. \& Lteif, A.N. 2013, "Female athlete triad and its components: toward improved screening and management", Mayo Clinic proceedings, vol. 88, no. 9, pp. 996-1009.

Jones, R.L., Glintmeyer, N. \& McKenzie, A. 2005, "Slim Bodies, Eating Disorders and the CoachAthlete Relationship A Tale of Identity Creation and Disruption", International review for the sociology of sport, vol. 40, no. 3, pp. 377-391.

Joy, E., De Souza, M.J., Nattiv, A., Misra, M., Williams, N.I., Mallinson, R.J., Gibbs, J.C., Olmsted, M., Goolsby, M., Matheson, G., Barrack, M., Burke, L., Drinkwater, B., Lebrun, C., Loucks, A.B., Mountjoy, M., Nichols, J. \& Borgen, J.S. 2014, "2014 Female Athlete Triad Coalition Consensus Statement on Treatment and Return to Play of the Female Athlete Triad", Current sports medicine reports, vol. 13, no. 4, pp. 219-232.

Joy, E.A., Wilson, C. \& Varechok, S. 2003, "The multidisciplinary team approach to the outpatient treatment of disordered eating", Current sports medicine reports, vol. 2, no. 6, pp. 331-336.

Juarascio, A.S., Forman, E.M. \& Herbert, J.D. 2010, "Acceptance and commitment therapy versus cognitive therapy for the treatment of comorbid eating pathology", Behavior modification, vol. 34, no. 2, pp. 175-190.

Kerr, G., Berman, E. \& Souza, M.J.D. 2006, "Disordered eating in women's gymnastics: Perspectives of athletes, coaches, parents, and judges", Journal of Applied Sport Psychology, vol. 18 , no. 1 , pp. $28-43$. 
Klump, K.L., Kaye, W.H. \& Strober, M. 2001, "The evolving genetic foundations of eating disorders", The Psychiatric clinics of North America, vol. 24, no. 2, pp. 215-225.

Knapp, J., Aerni, G. \& Anderson, J. 2014, "Eating disorders in female athletes: use of screening tools", Current sports medicine reports, vol. 13, no. 4, pp. 214-218.

Kristeller, J.L., Baer, R.A. \& Quillian-Wolever, R. 2006, "Mindfulness-based approaches to eating disorders", Mindfulness-based treatment approaches: Clinician's guide to evidence base and applications, , pp. 75-91.

Krones, P.G., Stice, E., Batres, C. \& Orjada, K. 2005, "In vivo social comparison to a thin-ideal peer promotes body dissatisfaction: a randomized experiment", The International journal of eating disorders, vol. 38, no. 2, pp. 134-142.

Kroshus, E., Sherman, R.T., Thompson, R.A., Sossin, K. \& Austin, S.B. 2014, "Gender differences in high school coaches' knowledge, attitudes, and communication about the female athlete triad", Eating disorders, vol. 22, no. 3, pp. 193-208.

Levine, M.P. \& Smolak, L. 2007, "Prevention of negative body image, disordered eating, and eating disorders: an update", Annual Review of Eating Disorders.United Kingdon: Radcliffe Publishing, , pp. 1-13.

Levitt, D.H. 2008, "Participation in athletic activities and eating disordered behavior", Eating disorders, vol. 16, no. 5, pp. 393-404.

Liberati, A., Altman, D.G., Tetzlaff, J., Mulrow, C., Gøtzsche, P.C., loannidis, J.P., Clarke, M., Devereaux, P., Kleijnen, J. \& Moher, D. 2009, "The PRISMA statement for reporting systematic reviews and meta-analyses of studies that evaluate health care interventions: explanation and elaboration", Annals of Internal Medicine, vol. 151, no. 4, pp. W-65-W-94.

Loucks, A.B. 2007, "Energy availability and infertility", Current opinion in endocrinology, diabetes, and obesity, vol. 14, no. 6, pp. 470-474.

Maïano, C., Morin, A.J., Lanfranchi, M. \& Therme, P. 2013, "The Eating Attitudes Test-26 revisited using exploratory structural equation modeling", Journal of abnormal child psychology, vol. 41, no. 5, pp. 775-788. 
Mallinson, R.J. \& De Souza, M.J. 2014, "Current perspectives on the etiology and manifestation of the "silent" component of the Female Athlete Triad", International journal of women's health, vol. 6, pp. 451-467.

Manore, M.M., Kam, L.C., Loucks, A.B. \& International Association of Athletics Federations 2007, "The female athlete triad: components, nutrition issues, and health consequences", Journal of sports sciences, vol. 25 Suppl 1, pp. S61-71.

Marquez, S. 2008, "Eating disorders in sports: risk factors, health consequences, treatment and prevention", Nutricion hospitalaria, vol. 23, no. 3, pp. 183-190.

Marquez, S. \& Molinero, O. 2013, "Energy availability, menstrual dysfunction and bone health in sports; an overview of the female athlete triad", Nutricion hospitalaria, vol. 28, no. 4, pp. 10101017.

Martinsen, M., Bahr, R., Borresen, R., Holme, I., Pensgaard, A.M. \& Sundgot-Borgen, J. 2014, "Preventing eating disorders among young elite athletes: a randomized controlled trial", Medicine and science in sports and exercise, vol. 46, no. 3, pp. 435-447.

Martinsen, M., Holme, I., Pensgaard, A.M., Torstveit, M.K. \& Sundgot-Borgen, J. 2014, "The development of the brief eating disorder in athletes questionnaire", Medicine and science in sports and exercise, vol. 46, no. 8, pp. 1666-1675.

Martinsen, M., Sherman, R.T., Thompson, R.A. \& Sundgot-Borgen, J. 2014, "Coaches' Knowledge and Management of Eating Disorders: A Randomized Controlled Trial", Medicine and science in sports and exercise, .

Martinsen, M. \& Sundgot-Borgen, J. 2013, "Higher prevalence of eating disorders among adolescent elite athletes than controls", Medicine and science in sports and exercise, vol. 45, no. 6 , pp. 1188-1197.

Matusek, J.A., Wendt, S.J. \& Wiseman, C.V. 2004, "Dissonance thin-ideal and didactic healthy behavior eating disorder prevention programs: Results from a controlled trial", International Journal of Eating Disorders, vol. 36, no. 4, pp. 376-388. 
Mazzeo, S.E., Slof-Op't Landt, M.C., Jones, I., Mitchell, K., Kendler, K.S., Neale, M.C., Aggen, S.H. \& Bulik, C.M. 2006, "Associations among postpartum depression, eating disorders, and perfectionism in a population-based sample of adult women", The International journal of eating disorders, vol. 39, no. 3, pp. 202-211.

McManus, S., Meltzer, H., Brugha, T., Bebbington, P. \& Jenkins, R. 2009, "Adult psychiatric morbidity in England, 2007: results of a household survey".

McNulty, K.Y., Adams, C.H., Anderson, J.M. \& Affenito, S.G. 2001, "Development and validation of a screening tool to identify eating disorders in female athletes", Journal of the American Dietetic Association, vol. 101, no. 8, pp. 886-892.

Melin, A., Tornberg, Å.B., Skouby, S., Møller, S.S., Sundgot-Borgen, J., Faber, J., Sidelmann, J.J., Aziz, M. \& Sjödin, A. 2014, "Energy availability and the female athlete triad in elite endurance athletes", Scandinavian Journal of Medicine \& Science in Sports, .

Melin, A., Tornberg, A.B., Skouby, S., Faber, J., Ritz, C., Sjodin, A. \& Sundgot-Borgen, J. 2014, "The LEAF questionnaire: a screening tool for the identification of female athletes at risk for the female athlete triad", British journal of sports medicine, vol. 48, no. 7, pp. 540-545.

Melin, A., Torstveit, M.K., Burke, L., Marks, S. \& Sundgot-Borgen, J. 2014, "Disordered eating and eating disorders in aquatic sports", International Journal of Sport Nutrition and Exercise Metabolism, vol. 24, no. 4, pp. 450-459.

Mencias, T., Noon, M. \& Hoch, A.Z. 2012, "Female athlete triad screening in National Collegiate Athletic Association Division I athletes: is the preparticipation evaluation form effective?", Clinical journal of sport medicine : official journal of the Canadian Academy of Sport Medicine, vol. 22, no. 2, pp. 122-125.

Meyer, N.L., Sundgot-Borgen, J., Lohman, T.G., Ackland, T.R., Stewart, A.D., Maughan, R.J., Smith, S. \& Muller, W. 2013, "Body composition for health and performance: a survey of body composition assessment practice carried out by the Ad Hoc Research Working Group on Body Composition, Health and Performance under the auspices of the IOC Medical Commission", British journal of sports medicine, vol. 47, no. 16, pp. 1044-1053. 
Mond, J.M., Myers, T.C., Crosby, R.D., Hay, P.J., Rodgers, B., Morgan, J.F., Hubert Lacey, J. \& Mitchell, J.E. 2008, "Screening for eating disorders in primary care: EDE-Q versus SCOFF", Behaviour research and therapy, vol. 46, no. 5, pp. 612-622.

Morse, B. 2008, "Female distance runners and disordered eating", Mind Matters: The Wesleyan Journal of Psychology, vol. 3, pp. 29-38.

Mountjoy, M. 2008, "Weight control strategies of Olympic athletes striving for leanness: what can be done to make sport a safer environment?", Clinical journal of sport medicine : official journal of the Canadian Academy of Sport Medicine, vol. 18, no. 1, pp. 2-4.

Mountjoy, M., Sundgot-Borgen, J., Burke, L., Carter, S., Constantini, N., Lebrun, C., Meyer, N., Sherman, R., Steffen, K., Budgett, R. \& Ljungqvist, A. 2014, "The IOC consensus statement: beyond the Female Athlete Triad--Relative Energy Deficiency in Sport (RED-S)", British journal of sports medicine, vol. 48, no. 7, pp. 491-497.

Nagel, D.L., Black, D.R., Leverenz, L.J. \& Coster, D.C. 2000, "Evaluation of a screening test for female college athletes with eating disorders and disordered eating", Journal of athletic training, vol. 35, no. 4, pp. 431-440.

Nattiv, A., Loucks, A.B., Manore, M.M., Sanborn, C.F., Sundgot-Borgen, J., Warren, M.P. \& American College of Sports Medicine 2007, "American College of Sports Medicine position stand. The female athlete triad", Medicine and science in sports and exercise, vol. 39, no. 10, pp. 1867-1882.

Nazem, T.G. \& Ackerman, K.E. 2012, "The female athlete triad", Sports health, vol. 4, no. 4, pp. 302-311.

Nichols, J.F., Rauh, M.J., Lawson, M.J., Ji, M. \& Barkai, H.S. 2006, "Prevalence of the female athlete triad syndrome among high school athletes", Archives of Pediatrics \& Adolescent Medicine, vol. 160, no. 2, pp. 137-142.

Nowicka, P., Eli, K., Ng, J., Apitzsch, E. \& Sundgot-Borgen, J. 2013, "Moving from Knowledge to Action: A Qualitative Study of Elite Coaches' Capacity for Early Intervention in Cases of Eating Disorders", International Journal of Sports Science and Coaching, vol. 8, no. 2, pp. 343-356. 
Okano, G., Holmes, R.A., Mu, Z., Yang, P., Lin, Z. \& Nakai, Y. 2005, "Disordered eating in Japanese and Chinese female runners, rhythmic gymnasts and gymnasts", International Journal of Sports Medicine, vol. 26, no. 6, pp. 486-491.

Otis, C.L., Drinkwater, B., Johnson, M., Loucks, A. \& Wilmore, J. 1997, "American College of Sports Medicine position stand. The Female Athlete Triad", Medicine and science in sports and exercise, vol. 29, no. 5, pp. i-ix.

Ousley, L., Cordero, E.D. \& White, S. 2008, "Eating disorders and body image of undergraduate men", Journal of American College Health, vol. 56, no. 6, pp. 617-622.

Palao, J.M., Gutierrez, D. \& Frideres, J.E. 2008, "Height, weight, Body Mass Index, and age in beach volleyball players in relation to level and position", The Journal of sports medicine and physical fitness, vol. 48, no. 4, pp. 466-471.

Pantano, K.J. 2006, "Current knowledge, perceptions, and interventions used by collegiate coaches in the u.s. Regarding the prevention and treatment of the female athlete triad", North American journal of sports physical therapy : NAJSPT, vol. 1, no. 4, pp. 195-207.

Patel, D.R., Greydanus, D.E., Pratt, H.D. \& Phillips, E.L. 2003, "Eating disorders in adolescent athletes", Journal of Adolescent Research, vol. 18, no. 3, pp. 280-296.

Perry, L., Morgan, J., Reid, F., Brunton, J., O'Brien, A., Luck, A. \& Lacey, H. 2002, "Screening for symptoms of eating disorders: reliability of the SCOFF screening tool with written compared to oral delivery", International Journal of Eating Disorders, vol. 32, no. 4, pp. 466-472.

Petrie, T.A. \& Greenleaf, C.A. 2007, "Eating disorders in sport", Handbook of sport psychology, , pp. 352-378.

Petrie, T.A., Greenleaf, C., Reel, J. \& Carter, J. 2008, "Prevalence of eating disorders and disordered eating behaviors among male collegiate athletes.", Psychology of Men \& Masculinity, vol. 9, no. 4, pp. 267.

Plateau, C.R., McDermott, H.J., Arcelus, J. \& Meyer, C. 2013, "Identifying and preventing disordered eating among athletes: Perceptions of track and field coaches", Psychology of Sport and Exercise, . 
Plateau, C.R., Arcelus, J., McDermott, H.J. \& Meyer, C. 2014, "Responses of track and field coaches to athletes with eating problems", Scandinavian Journal of Medicine \& Science in Sports, .

Presnell, K., Stice, E., Seidel, A. \& Madeley, M.C. 2009, "Depression and eating pathology: prospective reciprocal relations in adolescents", Clinical psychology \& psychotherapy, vol. 16, no. 4, pp. 357-365.

Quah, Y.V., Poh, B.K., Ng, L.O. \& Noor, M.I. 2009, "The female athlete triad among elite Malaysian athletes: prevalence and associated factors", Asia Pacific Journal of Clinical Nutrition, vol. 18, no. 2, pp. 200.

Raglin, J.S. \& Wilson, G.S. 2000, "Overtraining in athletes".

Ranby, K.W., Aiken, L.S., Mackinnon, D.P., Elliot, D.L., Moe, E.L., McGinnis, W. \& Goldberg, L. 2009, "A mediation analysis of the ATHENA intervention for female athletes: prevention of athletic-enhancing substance use and unhealthy weight loss behaviors", Journal of pediatric psychology, vol. 34, no. 10, pp. 1069-1083.

Reel, J.J., SooHoo, S., Petrie, T.A., Greenleaf, C. \& Carter, J.E. 2010, "Slimming down for sport: Developing a weight pressures in sport measure for female athletes", Journal of Clinical Sport Psychology, vol. 4, no. 2, pp. 99-111.

Reel, J.J., Greenleaf, C., Baker, W.K., Aragon, S., Bishop, D., Cachaper, C., Handwerk, P., Locicero, J., Rathburn, L., Reid, W.K. \& Hattie, J. 2007, "Relations of body concerns and exercise behavior: a meta-analysis", Psychological reports, vol. 101, no. 3 Pt 1, pp. 927-942.

Reinking, M.F. \& Alexander, L.E. 2005, "Prevalence of Disordered-Eating Behaviors in Undergraduate Female Collegiate Athletes and Nonathletes", Journal of athletic training, vol. 40 , no. 1 , pp. $47-51$.

Rouveix, M., Bouget, M., Pannafieux, C., Champely, S. \& Filaire, E. 2007, "Eating attitudes, body esteem, perfectionism and anxiety of judo athletes and nonathletes", International Journal of Sports Medicine, vol. 28, no. 4, pp. 340-345. 
Rumball, J.S. \& Lebrun, C.M. 2005, "Use of the preparticipation physical examination form to screen for the female athlete triad in Canadian interuniversity sport universities", Clinical journal of sport medicine : official journal of the Canadian Academy of Sport Medicine, vol. 15, no. 5, pp. 320-325.

Safer, D.L., Telch, C.F. \& Agras, W.S. 2001, "Dialectical behavior therapy for bulimia nervosa", American Journal of Psychiatry, vol. 158, no. 4, pp. 632-634.

Sanford-Martens, T.C., Davidson, M.M., Yakushko, O.F., Martens, M.P. \& Hinton, P. 2005, "Clinical and subclinical eating disorders: An examination of collegiate athletes", Journal of Applied Sport Psychology, vol. 17, no. 1, pp. 79-86.

Schtscherbyna, A., Soares, E.A., de Oliveira, F.P. \& Ribeiro, B.G. 2009, "Female athlete triad in elite swimmers of the city of Rio de Janeiro, Brazil", Nutrition (Burbank, Los Angeles County, Calif.), vol. 25, no. 6, pp. 634-639.

Schwarz, H.C., Gairrett, R.L., Aruguete, M.S. \& Gold, E.S. 2005, "Eating Attitudes, Body Dissatisfaction, and Perfectionism in Female College Athletes.", North American Journal of Psychology, vol. 7, no. 3.

Scoffier, S., Maïano, C. \& d'Arripe-Longueville, F. 2010, "The effects of social relationships and acceptance on disturbed eating attitudes in elite adolescent female athletes: The mediating role of physical self-perceptions", International journal of eating disorders, vol. 43, no. 1, pp. 65-71.

Selby, C.L. \& Reel, J.J. 2011, "A coach's guide to identifying and helping athletes with eating disorders", Journal of Sport Psychology in Action, vol. 2, no. 2, pp. 100-112.

Shanmugam, V., Jowett, S. \& Meyer, C. 2014, "Interpersonal difficulties as a risk factor for athletes' eating psychopathology", Scandinavian Journal of Medicine \& Science in Sports, vol. 24, no. 2, pp. 469-476.

Shanmugam, V., Jowett, S. \& Meyer, C. 2012, "Eating psychopathology amongst athletes: links to current attachment styles", Eating Behaviors, vol. 13, no. 1, pp. 5-12. 
Shapiro, J.R., Berkman, N.D., Brownley, K.A., Sedway, J.A., Lohr, K.N. \& Bulik, C.M. 2007, "Bulimia nervosa treatment: a systematic review of randomized controlled trials", International Journal of Eating Disorders, vol. 40, no. 4, pp. 321-336.

Sherman, R.T., Thompson, R.A., DeHass, D. \& Wilfert, M. 2005, "NCAA coaches survey: the role of the coach in identifying and managing athletes with disordered eating", Eating disorders, vol. 13 , no. 5, pp. 447-466.

Shultz, R., Bido, J., Shrier, I., Meeuwisse, W.H., Garza, D. \& Matheson, G.O. 2013, "Team clinician variability in return-to-play decisions", Clinical journal of sport medicine : official journal of the Canadian Academy of Sport Medicine, vol. 23, no. 6, pp. 456-461.

Smolak, L., Murnen, S.K. \& Ruble, A.E. 2000, "Female athletes and eating problems: a metaanalysis", The International journal of eating disorders, vol. 27, no. 4, pp. 371-380.

Sossin, K., Gizis, F., Marquart, L.F. \& Sobal, J. 1997, "Nutrition beliefs, attitudes, and resource use of high school wrestling coaches", International Journal of Sport Nutrition, vol. 7, no. 3, pp. 219-228.

Sport, UK. 2007, "Eating disorders in sport: A guideline framework for practitioners working with high performance athletes", UK Sport, .

Stewart, T., Plasencia, M., Han, H., Jackson, H. \& Becker, C. 2014, "Moderators and predictors of response to eating disorder risk factor reduction programs in collegiate female athletes", Psychology of Sport and Exercise, vol. 15, no. 6, pp. 713-720.

Stice, E. 1994, "Review of the evidence for a sociocultural model of bulimia nervosa and an exploration of the mechanisms of action", Clinical psychology review, vol. 14, no. 7, pp. 633661.

Stice, E., Marti, C.N., Spoor, S., Presnell, K. \& Shaw, H. 2008, "Dissonance and healthy weight eating disorder prevention programs: long-term effects from a randomized efficacy trial.", Journal of consulting and clinical psychology, vol. 76, no. 2, pp. 329. 
Stice, E., Maxfield, J. \& Wells, T. 2003, "Adverse effects of social pressure to be thin on young women: An experimental investigation of the effects of "fat talk"", International Journal of Eating Disorders, vol. 34, no. 1, pp. 108-117.

Stice, E. 2002, "Risk and maintenance factors for eating pathology: a meta-analytic review", Psychological bulletin, vol. 128, no. 5, pp. 825-848.

Stice, E., Mazotti, L., Weibel, D. \& Agras, W.S. 2000, "Dissonance prevention program decreases thin-ideal internalization, body dissatisfaction, dieting, negative affect, and bulimic symptoms: A preliminary experiment", The International journal of eating disorders, vol. 27, no. 2, pp. 206-217.

Stice, E. \& Shaw, H. 2004, "Eating disorder prevention programs: a meta-analytic review", Psychological bulletin, vol. 130, no. 2, pp. 206-227.

Stice, E., Shaw, H., Becker, C.B. \& Rohde, P. 2008, "Dissonance-based Interventions for the prevention of eating disorders: using persuasion principles to promote health", Prevention science : the official journal of the Society for Prevention Research, vol. 9, no. 2, pp. 114-128.

Stice, E., Trost, A. \& Chase, A. 2003, "Healthy weight control and dissonance-based eating disorder prevention programs: results from a controlled trial", The International journal of eating disorders, vol. 33, no. 1, pp. 10-21.

Striegel-Moore, R.H. \& Bulik, C.M. 2007, "Risk factors for eating disorders", The American Psychologist, vol. 62, no. 3, pp. 181-198.

Sudi, K., Ottl, K., Payerl, D., Baumgartl, P., Tauschmann, K. \& Muller, W. 2004, "Anorexia athletica", Nutrition (Burbank, Los Angeles County, Calif.), vol. 20, no. 7-8, pp. 657-661.

Sundgot-Borgen, J., Fasting, K., Brackenridge, C., Torstveit, M.K. \& Berglund, B. 2003, "Sexual harassment and eating disorders in female elite athletes-a controlled study", Scandinavian Journal of Medicine \& Science in Sports, vol. 13, no. 5, pp. 330-335.

Sundgot-Borgen, J. \& Torstveit, M. 2010, "Aspects of disordered eating continuum in elite highintensity sports", Scandinavian Journal of Medicine \& Science in Sports, vol. 20, no. s2, pp. 112-121. 
Sundgot-Borgen, J. 1996, "Eating disorders, energy intake, training volume, and menstrual function in high-level modern rhythmic gymnasts", International Journal of Sport Nutrition, vol. 6, no. 2, pp. 100-109.

Sundgot-Borgen, J. 1994, "Eating disorders in female athletes", Sports medicine (Auckland, N.Z.), vol. 17 , no. 3, pp. 176-188.

Sundgot-Borgen, J. 1994, "Risk and trigger factors for the development of eating disorders in female elite athletes", Medicine and science in sports and exercise, vol. 26, no. 4, pp. 414419.

Sundgot-Borgen, J. 1993, "Nutrient intake of female elite athletes suffering from eating disorders", International Journal of Sport Nutrition, vol. 3, no. 4, pp. 431-442.

Sundgot-Borgen, J. 1993, "Prevalence of eating disorders in elite female athletes", International Journal of Sport Nutrition, vol. 3, no. 1, pp. 29-40.

Sundgot-Borgen, J., Meyer, N.L., Lohman, T.G., Ackland, T.R., Maughan, R.J., Stewart, A.D. \& Muller, W. 2013, "How to minimise the health risks to athletes who compete in weight-sensitive sports review and position statement on behalf of the Ad Hoc Research Working Group on Body Composition, Health and Performance, under the auspices of the IOC Medical Commission", British journal of sports medicine, vol. 47, no. 16, pp. 1012-1022.

Sundgot-Borgen, J. \& Torstveit, M.K. 2010, "Aspects of disordered eating continuum in elite highintensity sports", Scandinavian Journal of Medicine \& Science in Sports, vol. 20 Suppl 2, pp. 112-121.

Sundgot-Borgen, J. \& Torstveit, M.K. 2007, "The female football player, disordered eating, menstrual function and bone health", British journal of sports medicine, vol. 41 Suppl 1, pp. i68-72.

Sundgot-Borgen, J. \& Torstveit, M.K. 2004, "Prevalence of eating disorders in elite athletes is higher than in the general population", Clinical journal of sport medicine : official journal of the Canadian Academy of Sport Medicine, vol. 14, no. 1, pp. 25-32. 
Swanson, S.A., Crow, S.J., Le Grange, D., Swendsen, J. \& Merikangas, K.R. 2011, "Prevalence and correlates of eating disorders in adolescents. Results from the national comorbidity survey replication adolescent supplement", Archives of General Psychiatry, vol. 68, no. 7, pp. 714-723.

Tamminen, K.A., Holt, N.L. \& Neely, K.C. 2013, "Exploring adversity and the potential for growth among elite female athletes", Psychology of Sport and Exercise, vol. 14, no. 1, pp. 28-36.

Telch, C.F., Agras, W.S. \& Linehan, M.M. 2001, "Dialectical behavior therapy for binge eating disorder.", Journal of consulting and clinical psychology, vol. 69, no. 6, pp. 1061.

Thompson, R.A. \& Sherman, R.T. 2011, Eating disorders in sport, Routledge.

Thompson, R.A. \& Sherman, R.T. 2005, "Athletes, eating disorders, and the four-minute mile", Eating disorders, vol. 13, no. 3, pp. 321-324.

Thompson, S.H. 2007, "Characteristics of the female athlete triad in collegiate cross-country runners", Journal of American college health : J of ACH, vol. 56, no. 2, pp. 129-136.

Toro, J., Galilea, B., Martinez-Mallen, E., Salamero, M., Capdevila, L., Mari, J., Mayolas, J. \& Toro, E. 2005, "Eating disorders in Spanish female athletes", International Journal of Sports Medicine, vol. 26, no. 8, pp. 693-700.

Torres-McGehee, T.M., Leaver-Dunn, D., Green, J.M., Bishop, P.A., Leeper, J.D. \& Richardson, M.T. 2011, "Knowledge of eating disorders among collegiate administrators, coaches, and auxiliary dancers", Perceptual and motor skills, vol. 112, no. 3, pp. 951-958.

Torres-McGehee, T.M., Monsma, E.V., Dompier, T.P. \& Washburn, S.A. 2012, "Eating disorder risk and the role of clothing in collegiate cheerleaders' body images", Journal of athletic training, vol. 47, no. 5, pp. 541-548.

Torres-McGehee, T.M., Monsma, E.V., Gay, J.L., Minton, D.M. \& Mady-Foster, A.N. 2011, "Prevalence of eating disorder risk and body image distortion among National Collegiate Athletic Association Division I varsity equestrian athletes", Journal of athletic training, vol. 46, no. 4 , pp. 431-437. 
Torres-McGehee, T.M., Pritchett, K.L., Zippel, D., Minton, D.M., Cellamare, A. \& Sibilia, M. 2012, "Sports nutrition knowledge among collegiate athletes, coaches, athletic trainers, and strength and conditioning specialists", Journal of athletic training, vol. 47, no. 2, pp. 205-211.

Torstveit, M.K., Rosenvinge, J.H. \& Sundgot-Borgen, J. 2008, "Prevalence of eating disorders and the predictive power of risk models in female elite athletes: a controlled study", Scandinavian Journal of Medicine \& Science in Sports, vol. 18, no. 1, pp. 108-118.

Torstveit, M.K. \& Sundgot-Borgen, J. 2005, "The female athlete triad exists in both elite athletes and controls", Medicine and science in sports and exercise, vol. 37, no. 9, pp. 1449-1459.

Torstveit, M.K. \& Sundgot-Borgen, J. 2005, "The female athlete triad: are elite athletes at increased risk?", Medicine and science in sports and exercise, vol. 37, no. 2, pp. 184-193.

Torstveit, M.K. \& Sundgot-Borgen, J. 2005, "Participation in leanness sports but not training volume is associated with menstrual dysfunction: a national survey of 1276 elite athletes and controls", British journal of sports medicine, vol. 39, no. 3, pp. 141-147.

Tozzi, F., Thornton, L.M., Klump, K.L., Fichter, M.M., Halmi, K.A., Kaplan, A.S., Strober, M., Woodside, D.B., Crow, S., Mitchell, J., Rotondo, A., Mauri, M., Cassano, G., Keel, P., Plotnicov, K.H., Pollice, C., Lilenfeld, L.R., Berrettini, W.H., Bulik, C.M. \& Kaye, W.H. 2005, "Symptom fluctuation in eating disorders: correlates of diagnostic crossover", The American Journal of Psychiatry, vol. 162, no. 4, pp. 732-740.

Troop, N.A., Allan, S., Treasure, J.L. \& Katzman, M. 2003, "Social comparison and submissive behaviour in eating disorder patients", Psychology and psychotherapy, vol. 76, no. Pt 3, pp. 237-249.

Troy, K., Hoch, A.Z. \& Stavrakos, J.E. 2006, "Awareness and comfort in treating the Female Athlete Triad: are we failing our athletes?", WMJ : official publication of the State Medical Society of Wisconsin, vol. 105, no. 7, pp. 21-24.

Turk, J.C., Prentice, W.E., Chappell, S. \& Shields, E.W. 1999, "Collegiate coaches' knowledge of eating disorders", Journal of athletic training, vol. 34, no. 1, pp. 19-24. 
Túry, F., Güleç, H. \& Kohls, E. 2010, "Assessment methods for eating disorders and body image disorders", Journal of psychosomatic research, vol. 69, no. 6, pp. 601-611.

Tylka, T.L. \& Subich, L.M. 2004, "Examining a Multidimensional Model of Eating Disorder Symptomatology Among College Women.", Journal of Counseling Psychology, vol. 51, no. 3, pp. 314.

Van Zyl, Y., Surujlal, J. \& Dhurup, M. 2012, "Eating disorders among university student-athletes: health and physical activity", African Journal for Physical Health Education, Recreation and Dance, vol. 18, no. 2, pp. 267-280.

Vaquero-Cristobal, R., Alacid, F., Muyor, J.M. \& Lopez-Minarro, P.A. 2013, "Body image; literature review", Nutricion hospitalaria, vol. 28, no. 1, pp. 27-35.

Vardar, S.A., Vardar, E., Altun, G.D., Kurt, C. \& Öztürk, L. 2005, "Prevalence of the female athlete triad in Edirne, Turkey", Journal of sports science \& medicine, vol. 4, no. 4, pp. 550.

Vaughan, J.L., King, K.A. \& Cottrell, R.R. 2004, "Collegiate Athletic Trainers' Confidence in Helping Female Athletes With Eating Disorders", Journal of athletic training, vol. 39, no. 1, pp. 71-76.

Wasilenko, K.A., Kulik, J.A. \& Wanic, R.A. 2007, "Effects of social comparisons with peers on women's body satisfaction and exercise behavior", The International journal of eating disorders, vol. 40, no. 8, pp. 740-745.

Wheatley, S., Khan, S., Székely, A.D., Naughton, D.P. \& Petróczi, A. 2012, "Expanding the female athlete triad concept to address a public health issue", Performance Enhancement \& Health, vol. 1, no. 1, pp. 10-27.

Whisenhunt, B.L., Williamson, D.A., Drab-Hudson, D.L. \& Walden, H. 2008, "Intervening with coaches to promote awareness and prevention of weight pressures in cheerleaders", Eating and weight disorders : EWD, vol. 13, no. 2, pp. 102-110.

Wiersma, L.D. \& Sherman, C.P. 2005, "Volunteer youth sport coaches' perspectives of coaching education/certification and parental codes of conduct", Research quarterly for exercise and sport, vol. 76, no. 3, pp. 324-338. 
Wilson, G.T., Grilo, C.M. \& Vitousek, K.M. 2007, "Psychological treatment of eating disorders.", American Psychologist, vol. 62, no. 3, pp. 199.

Wittchen, H. \& Jacobi, F. 2005, "Size and burden of mental disorders in Europe-a critical review and appraisal of 27 studies", European neuropsychopharmacology, vol. 15, no. 4, pp. 357376.

Yager, Z., O' \& Dea, J.A. 2005, "The role of teachers and other educators in the prevention of eating disorders and child obesity: what are the issues?", Eating Disorders, vol. 13, no. 3, pp. 261-278.

Zach, K.N., Smith Machin, A.L. \& Hoch, A.Z. 2011, "Advances in management of the female athlete triad and eating disorders", Clinics in sports medicine, vol. 30, no. 3, pp. 551-573.

Zimmerman, T.S. 1999, "Using family systems theory to counsel the injured athlete", Counseling in sports medicine, pp. 111-126. 


\section{Appendices}




\section{Diagnostic Criteria for Anorexia Nervosa}

A. Restriction of energy intake relative to requirements leading to a significantly low body weight in the context of age, sex, developmental trajectory, and physical health

B. Intense fear of gaining weight or becoming fat, even though underweight C. Disturbance in the way in which one's body weight or shape is experienced, undue influence of body weight or shape on self-evaluation, or denial of the seriousness of the current low body weight

Subtypes:

Restricting type: During the last three months, the person has not engaged in recurrent episodes of binge eating or purging behaviour (self-induced vomiting, use of laxatives, diuretics or enemas).

Binge/Purge type: During the last three months, the person has engaged in recurrent episodes of binge eating or purging behaviour.

Source: American Psychiatric Association. (2013). Diagnostic and statistical manual of mental disorders (5th ed.). Washington, DC: American Psychiatric Association.

Appendix 2: DSM-V Diagnostic Criteria for Bulimia Nervosa

Diagnostic Criteria for Bulimia Nervosa

A. Recurrent episodes of binge eating characterized by both of the following:

1. Eating in a discrete amount of time (within a 2-hr period) large amounts of food

2. Sense of lack of control over eating during an episode

B. Recurrent inappropriate compensatory behavior to prevent weight gain (purging)

C. The binge eating and compensatory behaviours both occur, on average, at least once a week for three months

D. Self-evaluation is unduly influenced by body shape and weight

E. The disturbance does not occur exclusively during episodes of anorexia nervosa

Source: American Psychiatric Association. (2013). Diagnostic and statistical manual of mental disorders (5th ed.). Washington, DC: American Psychiatric Association. 


\section{Diagnostic Criteria for Binge-Eating Disorder}

A. Recurrent episodes of binge eating. An episode of binge eating is characterized by both of the following:

1. Eating, in a discrete period of time (for example, within any 2-hr period), an amount of food that is definitely larger than most people would eat in a similar period of time under similar circumstances

2. A sense of lack of control over eating during the episode (for example, a feeling that one cannot stop eating or control what or how much one is eating)

B. The binge-eating episodes are associated with three (or more) of the following:

1. Eating much more rapidly than normal

2. Eating until feeling uncomfortably full

3. Eating large amounts of food when not feeling physically hungry

4. Eating alone because of feeling embarrassed by how much one is eating

5. Feeling disgusted with oneself, depressed, or very guilty afterward

C. Marked distress regarding binge eating is present

D. The binge eating occurs, on average, at least once a week for three months

$E$. The binge eating is not associated with the recurrent use of inappropriate compensatory behavior (for example, purging) and does not occur exclusively during the course Anorexia Nervosa, Bulimia Nervosa, or Avoidant/Restrictive Food Intake Disorder

Source: American Psychiatric Association. (2013). Diagnostic and statistical manual of mental disorders (5th ed.). Washington, DC: American Psychiatric Association. 


\section{Diagnostic Criteria for OSFED}

1. Atypical anorexia nervosa: All of the criteria for anorexia nervosa are met, except that despite significant weight loss, the individual's weight is within or above the normal range

2. Bulimia nervosa (of low frequency and/or limited duration): All of the criteria for bulimia nervosa are met, except that the binge eating and inappropriate compensatory behaviours occur, on average, less than once a week and/or for less than 3 months.

3. Binge-eating disorder (of low frequency and/or limited duration): All of the criteria for bingeeating disorder are met, except the binge eating occurs, on average, less than once a week and/or for less than 3 months.

4. Purging disorder: Recurrent purging behavior to influence weight or shape (e.g., self-induced vomiting, misuse of laxatives, diuretics, or other medications) in the absence of binge eating 5. Night eating syndrome: Recurrent episodes of night eating, as manifested by eating after awakening from sleep or by excessive food consumption after the evening meal. There is awareness and recall of the eating. The night eating is not better explained by external influences such as changes in the individual's sleep-wake cycle or by local social norms. The night eating causes significant distress and/or impairment in functioning. The disordered pattern of eating is not better explained by binge eating disorder or another mental disorder, including substance use, and is not attributable to another medical disorder or to an effect of medication.

Source: American Psychiatric Association. (2013). Diagnostic and statistical manual of mental disorders (5th ed.). Washington, DC: American Psychiatric Association. 
Dieting (unnecessary for health, sports performance, or appearance)

Self-critical; especially concerning body weight, size and shape in addition to performance

Avoidance of eating and eating situations

Secretive eating

Ritualistic eating patterns

Claims of "feeling fat" despite being thin (b)

Resistance to weight gain or maintenance recommended by medical providers

Unusual weighing behavior (i.e., excessive weighing, refusal to weigh for health or safety reasons, negative reaction to being weighed)

Compulsiveness and rigidity, especially regarding eating and exercising Excessive or obligatory exercise beyond that recommended for training or performance

Exercising while injured despite medically prescribed activity restrictions

Restlessness; relaxing is difficult or impossible

Change in behavior from open, positive, and social to suspicious, untruthful, and sad

Social withdrawal

Depression and insomnia

Binge eating (c)

Agitation when binging is interrupted (c)

Evidence of vomiting unrelated to illness (c)

Excessive use of the restroom or "disappearing" after eating (c)

Use of laxatives or diuretics (or both) that is unsanctioned by medical providers (c)

Substance abuse, whether legal, illegal, prescribed, or over-the-counter drugs, medications, or other substances (c)

Source: Adapted from The Female Athlete, Mary Lloyd Ireland and Aurelia Nattiv (eds.), Jorunn Sundgot-Borgen, Disordered Eating, p. 243, (2002)

(b) Indicates especially for anorexia nervosa.

(c) Indicates especially for bulimia nervosa. 
Appendix 6: Physical Signs/Symptoms of Eating-Disordered Athletes

\section{Cardiovascular}

Bradycardia

Hypotension

Atrial and ventricular arrhythmias

Electrocardiographic abnormalities

Acrocyanosis

\section{Endocrine}

Hypoglycaemia

Decreased testosterone levels in males

Low female sex hormone levels

Amenorrhea or menstrual dysfunction

Reduced bone mineral density

Stress fractures

Delayed onset of puberty (b)

Short stature/arrested skeletal growth (b)

\section{Gastrointestinal}

Constipation, bloating, postprandial distress

Abdominal pain

Bowel irregularities

Fluids and Electrolytes

Dehydration

Electrolyte abnormalities

Hypokalaemia

Muscle cramps

Metabolic alkalosis

Oedema

\section{Thermoregulation}

Hypothermia (b)

\section{Hematologic}

Anaemia 


\section{Dermatologic}

Hair loss (b)

Dry skin, brittle hair and nails (b)

Lanugo (b)

Callus or abrasion on back of hand (from inducing vomiting) (c)

\section{Oral/facial}

Dental decay

Pain in pharynx

Swollen parotid glands (c)

\section{Others}

Significant weight loss (beyond that necessary for adequate sport

performance) (b)

Frequent and often extreme weight fluctuations (c)

Low weight despite eating large volumes (c)

Fatigue (beyond that normally expected in training or competition)

Muscle weakness

Source: Adapted from The Female Athlete, Mary Lloyd Ireland and Aurelia Nattiv (eds.), Jorunn Sundgot-Borgen, Disordered Eating, p. 242, 2002

(b) Indicates especially for anorexia nervosa.

(c) Indicates especially for bulimia. 


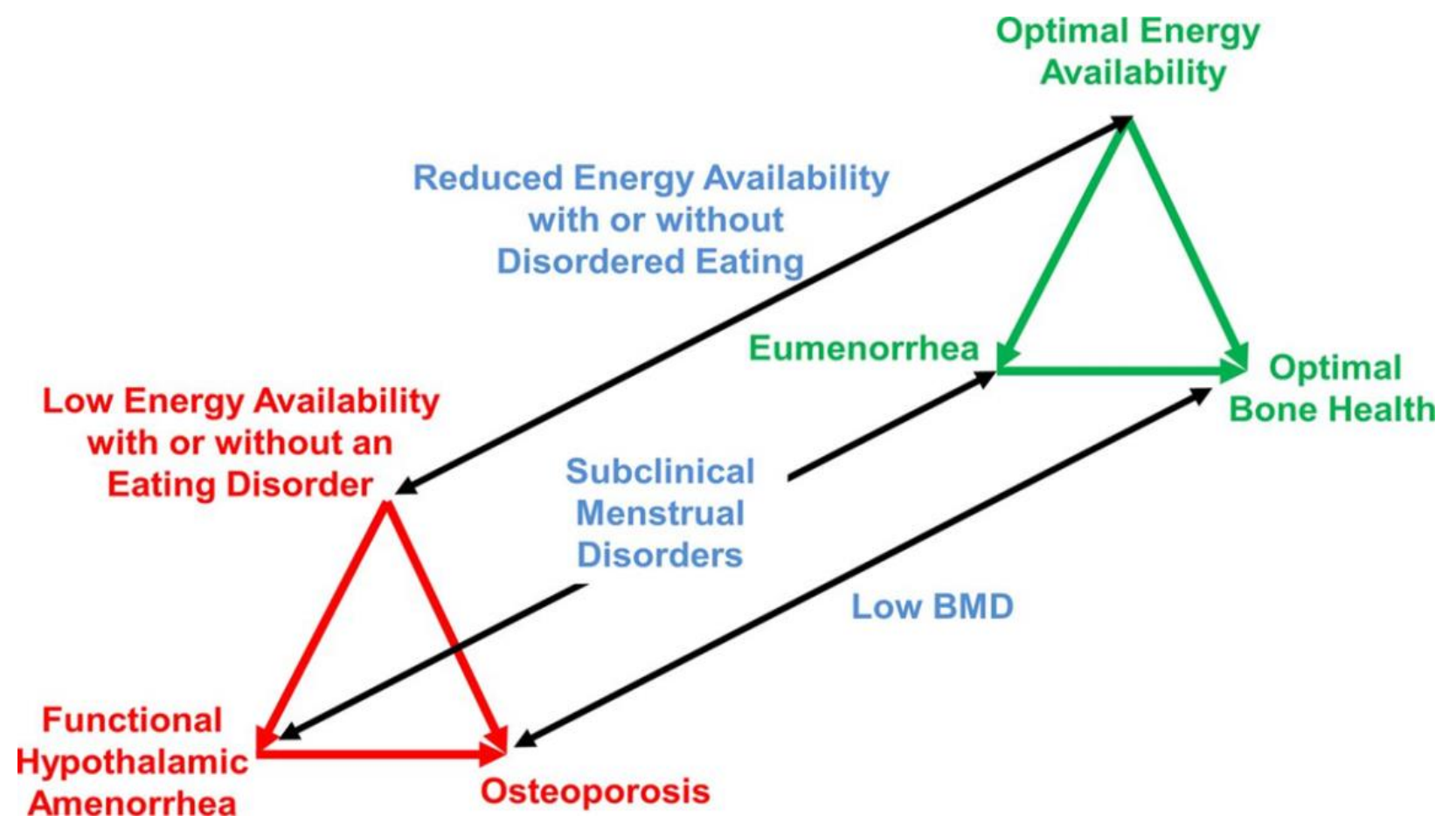

(Source: De Souza et al. 2014, adapted from Nattiv et al. 2007)

Spectrum of the Female Athlete Triad: The three inter-related components of the Female Athlete Triad are energy availability, menstrual status and bone health. Energy availability directly affects menstrual status, and in turn, energy availability and menstrual status directly influence bone health. Optimal health is indicated by optimal energy availability, eumenorrhoea and optimal bone health, whereas, at the other end of the spectrum, the most severe presentation of the Female Athlete Triad is characterised by low energy availability with or without an eating disorder, functional hypothalamic amenorrhoea and osteoporosis. An athlete's condition moves along each spectrum at different rates depending on her diet and exercise behaviours. 


\section{Appendix 8: Female Athlete Triad prevalence studies}

\begin{tabular}{|c|c|c|c|c|c|}
\hline Study & Population & Measurement & FAT Components & FAT & Other \\
\hline Hoch et al. 2009 & High school athletes \& Controls & $\begin{array}{l}\text { Screening questions } \& \\
3 \text { day food diary }\end{array}$ & $\begin{array}{l}36 \% \text { Low EA, } 54 \% \mathrm{MD}, \\
16 \% \text { Low BMD }\end{array}$ & $1.2 \%$ & $\begin{array}{l}30 \% \text { Low BMD \& } 1.2 \% \text { FA? } \\
\text { in controls }\end{array}$ \\
\hline Hoch et al. 2011 & Professional ballet dancers & $\begin{array}{l}\text { EDE-Q \& 3-Day food } \\
\text { Diary }\end{array}$ & $\begin{array}{l}77 \% \text { Low EA, } 36 \% \mathrm{MD}, \\
23 \% \text { Low BMD }\end{array}$ & $14 \%$ (+ED) & $\begin{array}{l}64 \% \text { abnormal brachial } \\
\text { artery flow-mediated dilation }\end{array}$ \\
\hline $\begin{array}{l}\text { Torstveit \& Sundgot- } \\
\text { Borgen } 2005\end{array}$ & $\begin{array}{l}\text { Elite Norwegian athletes } \\
13-39 \text { yrs. }\end{array}$ & $\begin{array}{l}\text { EDI-DT, EDI-BD, } \\
\text { Interviews }\end{array}$ & & $4.3 \%$ & $3.4 \%$ FAT in controls \\
\hline Nichols et al. 2006 & $\begin{array}{l}\text { High school athletes from } \\
8 \text { sports in California }\end{array}$ & EDE-Q & $\begin{array}{l}18.2 \% \text { DE, } 23.5 \% \mathrm{MD} \\
21.8 \% \text { Low BMD }\end{array}$ & $1.2 \%$ & \\
\hline Melin et al. 2014 & $\begin{array}{l}\text { Elite endurance athletes } \\
\text { In Scandinavia }\end{array}$ & EDE, 7-Day food diary & $\begin{array}{l}63 \% \text { Low EA, } 60 \% \text { MD, } \\
45 \% \text { Low BMD }\end{array}$ & $23 \%$ & $\begin{array}{l}25 \% \text { had clinical ED \& } \\
\text { Hypercholesterolemia }\end{array}$ \\
\hline Coelho et al. 2013 & $\begin{array}{l}\text { Adolescent Brazilian tennis } \\
\text { Players }\end{array}$ & EAT-26, BITE, BSQ & $\begin{array}{l}91.2 \% \text { Low EA, } 33.3 \% \text { MD, } \\
25 \% \text { Low BMD }\end{array}$ & $4.2 \%$ & \\
\hline Schtscherbyna et al. 2009 & $\begin{array}{l}\text { Elite Brazilian swimmers } \\
11-19 \text { yrs. }\end{array}$ & EAT-26, BITE, BSQ & $\begin{array}{l}44.9 \% \text { Low EA, } 19.2 \% \text { MD, } \\
15.4 \% \text { Low BMD }\end{array}$ & $1.3 \%$ & \\
\hline Quah et al. 2009 & $\begin{array}{l}\text { Elite Malaysian athletes } \\
13-30 \text { yrs. }\end{array}$ & EDI & $\begin{array}{l}\text { 89.2\% Low EA/DE, } 47.6 \% \text { MD } \\
13.3 \% \text { Low BMD }\end{array}$ & $1.9 \%$ & $\begin{array}{l}\text { Higher prevalence in lean } \\
\text { sport athletes }\end{array}$ \\
\hline Pollock et al. 2010 & Elite endurance runners & $\begin{array}{l}\text { Cross-sectional } \\
\text { Longtitudinal data }\end{array}$ & $34.2 \%$ Low BMD & $15.9 \%$ & $\begin{array}{l}33 \% \text { had osteoporosis at } \\
\text { radius }\end{array}$ \\
\hline Movaseghi et al. 2012 & Elite Iranian athletes & Clinical interviews & $9.2 \% \mathrm{MD}, 2 \%$ Stress fracture & $0.4 \%$ & $\begin{array}{l}1.4 \% \text { had polycystic ovary } \\
\text { Syndrome }\end{array}$ \\
\hline Vardar et al. 2005 & Turkish athletes in 10 sports & EAT-40 & 16.8\% DE, $9.8 \%$ Amenorrhea & $1.36 \%$ & \\
\hline
\end{tabular}




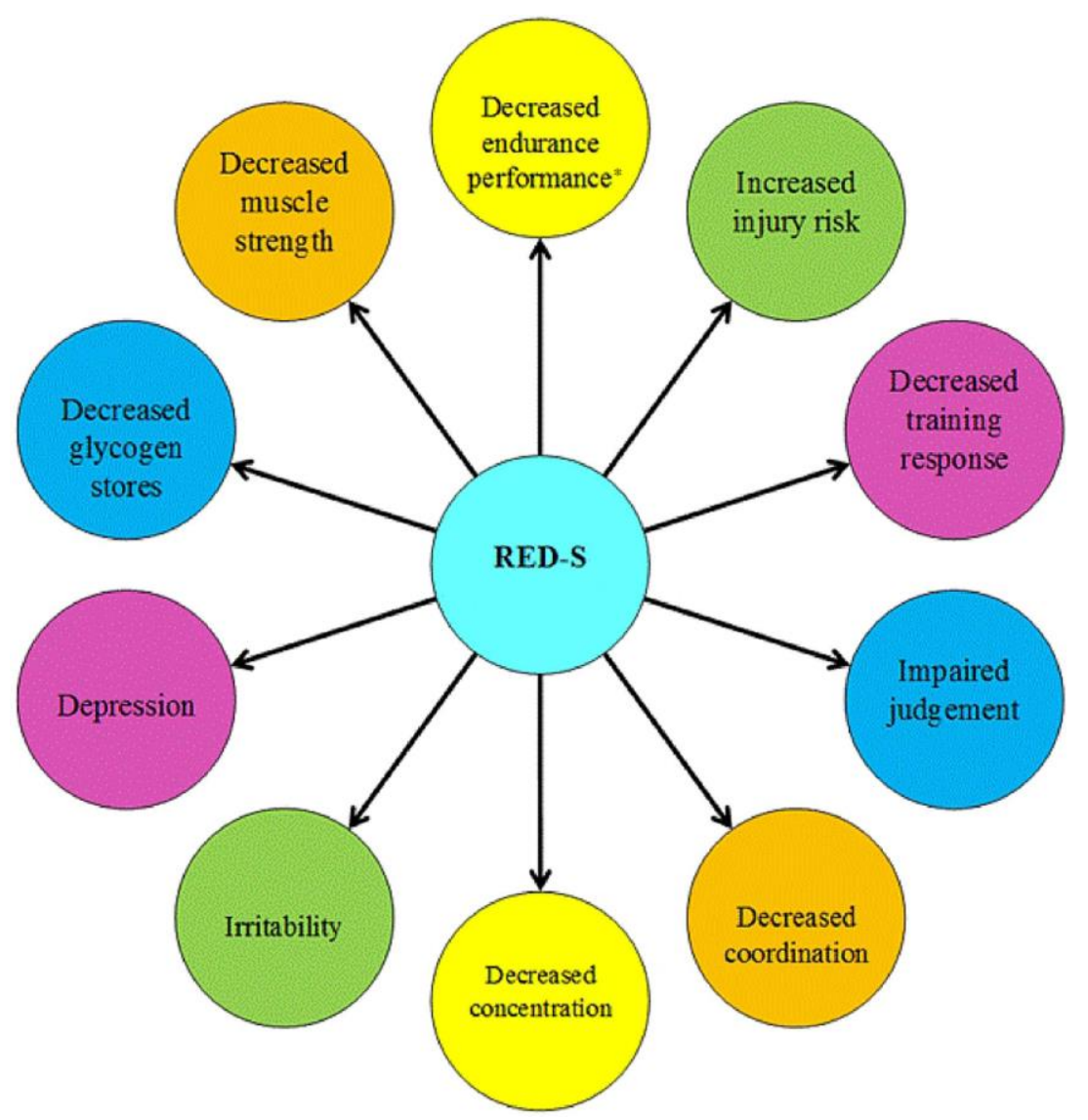

(Source: Mountjoy et al. 2014, Adapted from Constantini 2002) 
Appendix 10: Health Consequences of Relative Energy Deficiency in Sport (RED-S) showing an expanded concept of the Female Athlete Triad to acknowledge a wider range of outcomes and the application to male athletes.

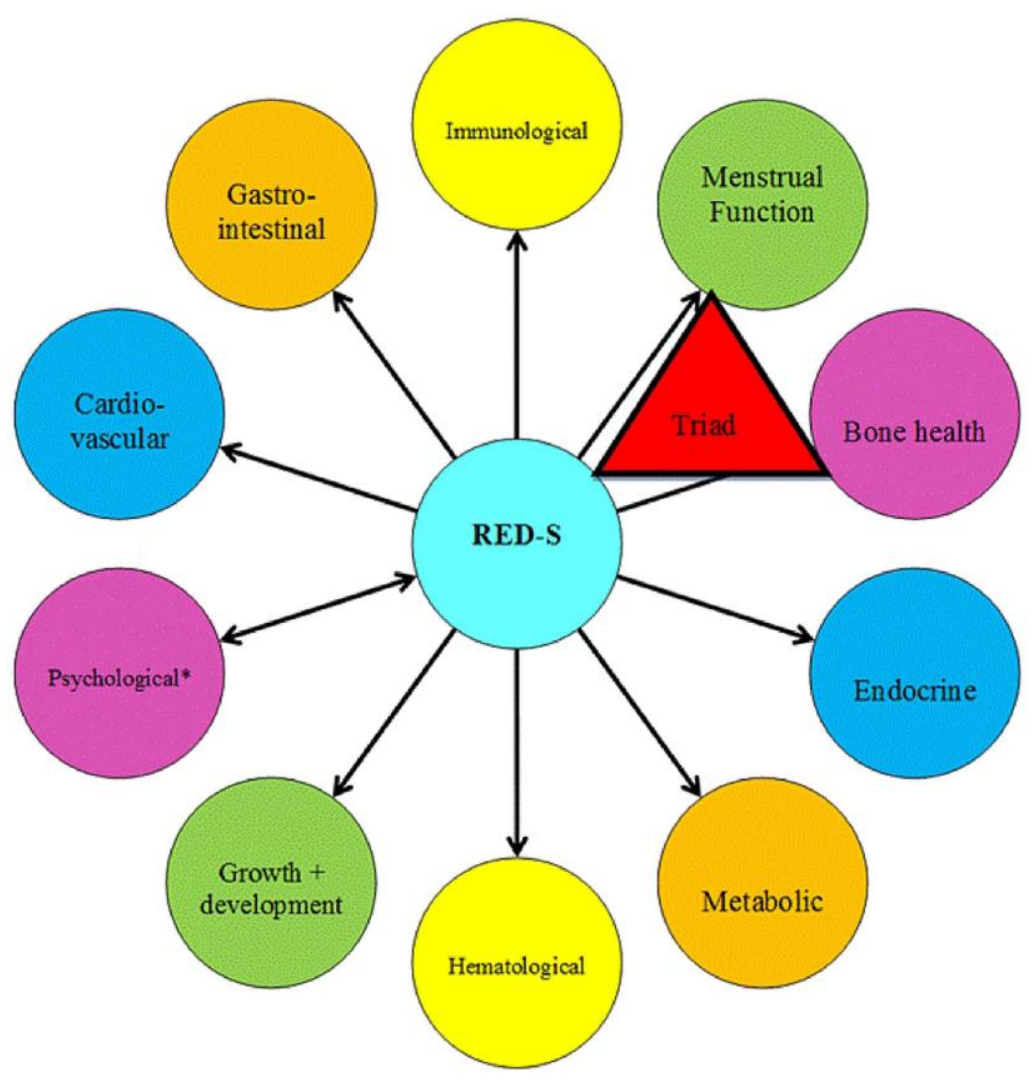

(Source: Mountjoy et al. 2014, Adapted from Constantini 2002) 


\section{Appendix 11: Etiological Model of Eating Disorder Risk Factors}

Source: Petrie and Greenleaf (2007)

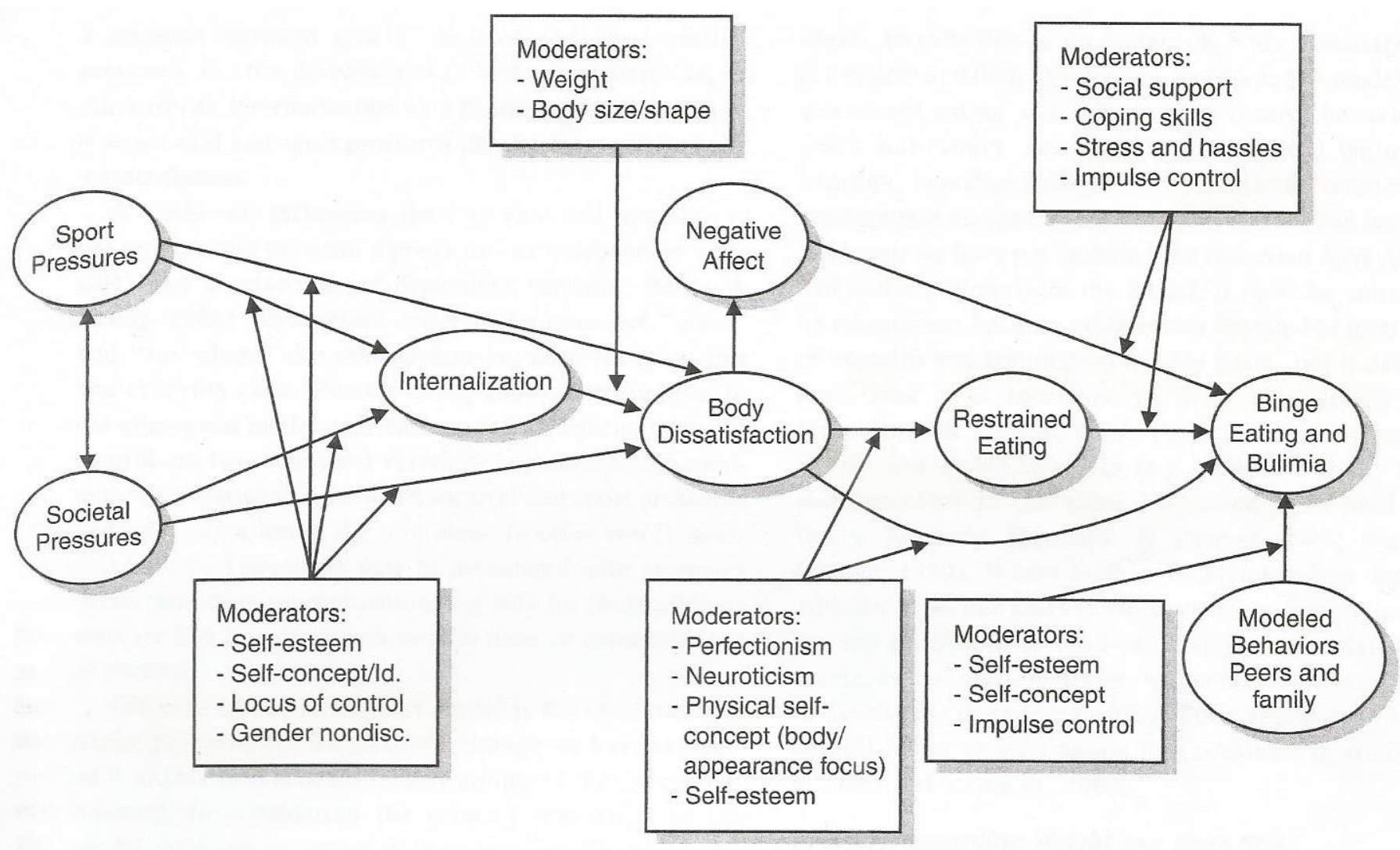




\begin{tabular}{|c|c|c|c|}
\hline Author & Population & Intervention & Results \\
\hline $\begin{array}{l}\text { Sundgot-Borgen \& } \\
\text { Kungland (1998) } \\
\end{array}$ & $\begin{array}{l}695 \text { Elite female } \\
\text { athletes, } 48 \text { sports }\end{array}$ & $\begin{array}{l}\text { Preventive educational work } \\
\text { aimed at ED. }\end{array}$ & $\begin{array}{l}\text { Prevalence of ED decreased, showing preventive } \\
\text { Work is effective. }\end{array}$ \\
\hline Elliot et al. (2004) & $\begin{array}{l}928 \text { athletes, } \\
40 \text { sports }\end{array}$ & $\begin{array}{l}\text { The ATHENA curriculum's } \\
8 \text { weekly, 45-min sessions }\end{array}$ & $\begin{array}{l}\text { ATHENA produced less health-harming behaviours. } \\
\text { Effective at promoting healthy lifestyles \& deterring ED. }\end{array}$ \\
\hline Elliot et al. (2006) & $\begin{array}{l}1,178 \text { young } \\
\text { Female athletes }\end{array}$ & $\begin{array}{l}\text { The ATHENA curriculum's } \\
8 \text { weekly, } 45 \text {-min sessions }\end{array}$ & $\begin{array}{l}\text { ATHENA produced less health-harming behaviours. } \\
\text { Effective at promoting healthy lifestyles \& deterring ED. }\end{array}$ \\
\hline Ranby et al. (2009) & $\begin{array}{l}1,668 \text { female } \\
\text { Athletes }\end{array}$ & $\begin{array}{l}\text { The ATHENA curriculum's } \\
8 \text { weekly, } 45 \text {-min sessions. }\end{array}$ & $\begin{array}{l}\text { Positive impact on knowledge, self-efficacy, social } \\
\text { Norms, mood \& intentions. Stronger effect on reducing } \\
\text { Intentions, than behaviours. }\end{array}$ \\
\hline Becker et al. (2012) & $\begin{array}{l}157 \text { female college } \\
\text { Athletes, } 9 \text { teams }\end{array}$ & $\begin{array}{l}\text { Athletes randomly assigned to } \\
\text { AM-DPB or AM-HWI. }\end{array}$ & $\begin{array}{l}\text { Both reduced dietary restraint, shape \& weight concern } \\
\& \text { negative affect. Both capable of reducing ED risk, but } \\
\text { HWI preferred by athletes. }\end{array}$ \\
\hline $\begin{array}{l}\text { Abood \& Black } \\
(2000)\end{array}$ & Female athletes & Health education intervention & $\begin{array}{l}\text { Intervention athletes scored lower on drive for thinness } \\
\& \text { body dissatisfaction. Controls had lower self-esteem } \\
\& \text { nutrition knowledge. }\end{array}$ \\
\hline $\begin{array}{l}\text { Bucholz et al. } \\
\text { (2008) }\end{array}$ & $\begin{array}{l}62 \text { young } \\
\text { female gymnasts }\end{array}$ & $\begin{array}{l}\text { Bodysense education } \\
\text { initiative }\end{array}$ & $\begin{array}{l}\text { Led to the perception of gymnasts feeling reduced } \\
\text { pressure about thinness. }\end{array}$ \\
\hline $\begin{array}{l}\text { Doyle-Lucas \& } \\
\text { Davy (2011) }\end{array}$ & $\begin{array}{l}321 \text { adolescent } \\
\text { ballet dancers }\end{array}$ & $\begin{array}{l}\text { Nutritional education } \\
\text { through } 3 \text { DVD lectures }\end{array}$ & $\begin{array}{l}\text { Effective at increasing nutrition knowledge, } \\
\text { FAT susceptibility \& self-efficacy constructs. }\end{array}$ \\
\hline $\begin{array}{l}\text { Matinsen et al. } \\
(2014)\end{array}$ & $\begin{array}{l}465 \text { elite female } \\
\text { adolescent athletes }\end{array}$ & $\begin{array}{l}\text { One year school-based } \\
\text { intervention, to increase } \\
\text { Motivation \& self-esteem }\end{array}$ & $\begin{array}{l}\text { There were no new cases of ED in intervention } \\
\text { schools, compared to } 13 \% \text { in control schools. } \\
\text { Reduced risk of reporting symptoms. }\end{array}$ \\
\hline
\end{tabular}




Intervention Evidence-based support Description

The Eating Attitudes

Test (EAT)

Garner \& Garfinkel (1979)

Garner et al. (1982)

Maiano et al. (2013)

Fairburn \& Cooper, 1993

Peterson \& Miller, 2005

Eating Disorde

Examination (EDE)

Mond et al. (2008)

Eating Disorder

$\begin{array}{ll}\text { Examination Questionnaire } & \text { Aardoom et al. (2012) } \\ \text { (EDE-Q) } & \text { Berg et al. (2012) }\end{array}$

Eating Disorder Inventory (EDI)

Garner \& Olmstead (1984)

Garner (2004)

SCOFF
Garcia-Campayo et al. (2005) Perry et al. (2002)

Hill et al. (2010)

Tury et al. (2010)
Originally developed in 1979 to test attitudes and behaviours found in AN. Updated to the EAT-26 in 1982, which displayed good validity and high internal consistency. Has been found to be reliable \& valid In adolescents and many languages.

Currently in its $16^{\text {th }}$ edition, its considered the gold standard in ED diagnosis. It's the most commonly used clinical interview to assess ED Characteristics. Allows for attainment of more specific information \& Reduces likelihood of false reporting.

Consists of a 36-item questionnaire derived from the EDE interview. It's been found to have internal consistency and reliability and has been validated for adults, but not adolescents or athletes.

Originally consisted of 64 questions \& 8 subscales to screen for AN \& BN. The latest version, the EDI-3, has been found to have good reliability \& validity and has been used extensively with athletes.

Consists of 5 questions addressing core characteristics of AN \& BN. Has been validated \& tested \& is regularly used in clinical practice, with high sensitivity, specificity \& validity. Has the advantage of being quick \& easily administered. 
Evidence-based Screening Interventions Specifically for Female Athletes

Intervention Evidence-based support

Female athlete screening McNulty et al. (2001)

Tool (FAST)

Athletic Milieu

Direct Questionnaire

Nagel et al. (2000)

Physiologic

Screening Tool

Black et al. (2003)

Brief Eating Disorders Martinsen et al. (2014)

in Athletes Questionnaire

Low Energy Availbility

Melin et al. (2014)

In Females Questionnaire

\section{Description}

A 33-item questionnaire designed for female athletes and has been validated in a collegiate population. The FAST can differentiate Athletes with performance-oriented behaviours \& those with disordered eating, identifying those at risk.

Self-report questionnaire designed for female athletes. Found to have high sensitivity, low rates of false-negatives, and a high negative predictive value, and good accuracy \& validity in female athletes.

An 18-item tool, consisting of 14 self-report questions and 4 physiologic measurements. Found to have good sensitivity, specificity \& low false-positive rate. May be implementation barriers.

Developed for high school female athletes. Has been found to show good ability to distinguish between female athletes with and without ED. Validated in adolescent population.

A 25-item questionnaire designed to detect low energy availability, and athletes at risk for FAT. It is brief and easily administered and was found to produce acceptable sensitivity \& specificity in classifying current FAT conditions. 
The SCOFF Questionnaire, devised by researchers at St George's Hospital Medical School, is a valid and reliable screening tool for detecting the existence of an eating disorder. The questions focus on some key characteristics of anorexia and bulimia.

* SCOFF Questionnaire *

1. Do you make yourself Sick because you feel uncomfortably full? Yes

No

2. Do you worry you have lost Control over how much you eat? Yes

No

3. Have you recently lost more than One stone in a 3 month period? Yes

No

4. Do you believe yourself to be Fat when others say you are too thin? Yes

No

5. Would you say that Food dominates your life?

Yes

No 
Interpretation of Results

If you answer 'No' to every question, the test indicates you do not have an eating disorder. If you still think you may have an eating disorder, see your doctor. If you answer 'Yes' to 1 question, with the rest answered as 'No', the test indicates you do not have an eating disorder. However, it does suggest you may have some issues with food or your body image. If you are in any doubt about whether or not you have an eating disorder, see your doctor. If you answered Yes to at least 2 questions, the test indicates you may have Anorexia Nervosa or Bulimia Nervosa. This is not a diagnosis, but it is possible you have an eating disorder that needs further investigation by a qualified health professional. Please see your doctor.

A further two questions have been shown to indicate a high sensitivity and specificity for bulimia nervosa. These questions indicate a need for further questioning and discussion.

1. Are you satisfied with your eating patterns?

2. Do you ever eat in secret?

Source: Luck, A.J., Morgan, J.F., Reid, F., O'Brien, A., Brunton, J., Price, C., Perry, L., Lacey,J.H. (2002), 'The SCOFF questionnaire and clinical interview for eating disorders in general practice: comparative study', British Medical Journal, 325,7367, 755 - 756. 
Appendix 15: Comparison of Pre-participation Evaluation (PPE) Items in the AAP/AAFP/ACSM PPE Form and the 12 Items Recommended by the Female Athlete Triad Coalition

Items recommended by the Female Athlete

Included in AAP/AAFP/ASCM PPE

Triad Coalition for screening on PPE forms

\section{Disordered eating}

Do you worry about your weight?

Yes

Do you limit the foods you eat?

Yes

Do you lose weight to meet image requirements for sports?

Yes

Does your weight affect the way you feel about yourself?

No

Do you feel you have lost control over what you eat?

No

Do you make yourself vomit or use laxatives or diuretics?

No

Have you ever suffered from an eating disorder?

Yes

Do you ever eat in secret?

No

\section{Menstrual dysfunction}

How old were you when you had your first menstrual period? Yes

Do you have monthly menstrual cycles? No

How many menstrual cycles have you had in the past 12 months? Yes

\section{Skeletal health}

Have you ever had a stress fracture?

Yes

AAP: American Academy of Pediatrics; AAFP: American Academy of Family Physicians; ACSM: American College of Sports Medicine.

Source: Javed et al. (2013) 
Therapy

Cognitive-Behavioural therapy (CBT); Beck (1970)

\section{Shapiro et al. (2007)}

Wilson et al. (2007)

Acceptance and Commitment Heffner et al. (2002)

Therapy (ACT); Hayes \&

Wilson (1994)

\section{Baer et al. (2005)} Kristeller et al. (2006)

Dialectical Behavioural therapy Safer et al. (2001)

(DBT); Linehan et al. (1993)

Telch et al. (2001)

Ben-Porath et al. (2009)

Enhanced Cognitive behavioural Fairburn et al. (2008)

Therapy (CBT-E); Fairburn

(2008)

Dissonance-based Prevention Matusek et al. (2004)

(DBP); Stice et al. (2008)
Green et al. (2005)

Becker et al. (2008)

Becker et al. (2010)
Focuses on identifying \& modifying thoughts, Gains an awareness of thoughts, mood emotions \& behaviours. Focuses on the present, shifts \& behaviours that are affecting food can be brief or long-term. choices, body image distortions \& weight.

Uses mindfulness \& acceptance strategies; observing \& experiencing opposed to directly modifying negative thoughts \& behaviours.

Begins to accept and embrace negative or uncomfortable thoughts toward eating and body image.

Targets emotional regulation by teaching adaptive skills to foster self-monitoring, regulating emotions, \& distress tolerance. Emphasizes acceptance \& change.

Observes emotional regulation cycle \& patterns, accepts environmental \& personal Cues that impact mood, disordered eating or body distortions \& take action.

Focuses on eating disorders and exploring

Identifies underlying thought processes \& low self-esteem \& perfectionism. Uses a highly personality characteristics contributing to structured yet personalized approach to tackling eating disorders. Explores impact on selfDysfunctional beliefs \& eating behaviour. esteem, mood \& relationships.

Identifies inconsistencies between body image Identifies \& discusses cultural \& sport body attitudes \& behaviours through activities, discussions \& body activism. Develops ideals; emotional \& physical costs. Identify alternative attitudes \& behaviours.

healthier attitudes \& behaviours.
Participate in body activism \& resisting ideals. 


\section{Disordered Eating Decision Tree}

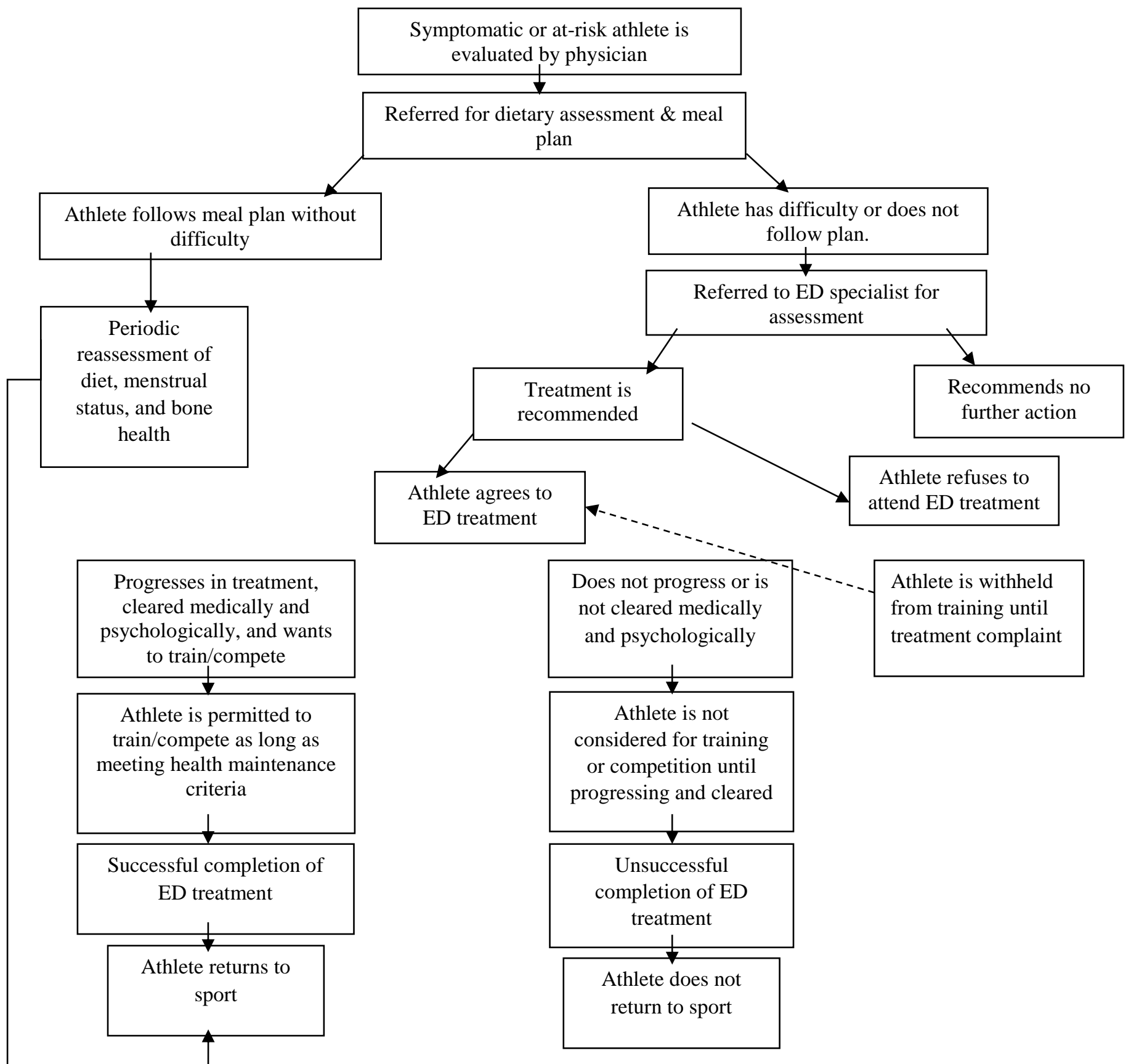

Source: IOC Position Stand on the Female Athlete Triad (2005)

\section{Appendix 18: Sample Athlete Contract for Coaches}


Sample Contractual Agreement for Continued Athletic Participation in the Active Phase of an Eating Disorder (Noncompliance)

Dear

As a representative of your health care team, I am pleased to inform you that your physical condition presently suggests no immediate health risk. However, it has been brought to my attention that you have not been complying fully with the treatment plan that has been formulated for you. I want to remind you how important it is to take the appropriate steps to care for yourself. Our health care team will do everything possible to assist you in this effort. To ensure that your health remains stable, your current athletics participation status for the remainder of the school year will be contingent on your compliance with the following:

1. Receive individual psychotherapy from once a week so that you can address all issues and find healthy ways to cope with them;

2. See Dr. for medical evaluation of your health status, including lab tests if necessary, every other week to ensure your physical well-being;

3. Participate in nutritional counselling sessions according to a schedule recommended by our registered dietician,

4. Maintain your body weight over pounds (if applicable).

Anticipate weekly monitoring of your weight if it falls below this level.

5. Sign and leave on file a release of information with permitting our health care professionals to communicate openly and freely with each other, members of the coaching staff, your parents, and your caregivers at home.

6. See your home-based physician and therapist during the winter and summer breaks. Prior to your return to campus, you're attending physician and therapist must send Dr. a letter indicating the following: (a) you are ready to return to school; (b) you have been in treatment; (c) you are ready to take on the academic, training, performance, and social challenges for the semester; and (d) you are taking any medication recommended and prescribed by your psychotherapist. This letter should be in the possession of Dr. prior to your arrival on campus in . Additionally, we would like you to talk with Dr. in person or by phone to discuss your plans for the semester and confirm your ability to return. Upon your return to campus, you should anticipate 
meeting with Dr. for a re-entry evaluation so that your medical status can be assessed, activity status determined, and further treatment options explored, if necessary.

7. Check-in routinely with your certified athletic trainer, , who will be available to assist you. (Athlete's Name), I am confident that you have the ability and support to address the health concerns that you are currently facing. It is our every expectation that you will comply with all necessary medical and personal advice to advance your recovery so that you can continue to flourish in this environment.

Please sign below verifying that you are prepared to comply with the stipulations outlined above.

Athlete's Signature Date

Sincerely,

(Athletics Administrator or Supervising Physician)

Source: Bonci et al. (2008) 
Appendix 19: Intervention Strategies used by Coaches

Specific Strategies used by coaches for the prevention of eating disorders in female athletes

Direct intervention by coaches with athlete:

- Educate athlete and team on healthy living and eating.

- Have open communication between the athlete and coach.

- Provide hand-outs on recent literature.

- Engage athlete/team in preseason discussions about eating disorders

- Immediately address the emotional needs of the athlete.

- May need to determine if athlete is in appropriate weight class for the sport and restrict supervised weigh-ins to lightweight rowing only.

- Avoid 'under-sizing' uniforms as they encourage the athlete to lose weight.

- A food journal or a menstrual cycle journal is required.

- All athletes are educated on the importance of nutrition. Provide packets of suggested meals and snacks that are easy to prepare on a budget and talk openly about drug and alcohol abuse.

- Remove athlete from competition if diagnosed as anorexic or bulimic.

- Weight lifting and impact sports are encouraged to increase bone mass.

Direct intervention by coaches with other healthcare professionals:

- Nutritionists consult athlete on a regular basis to discuss calcium, vitamin D and nutritional needs.

- Coaches, doctors, physiotherapists and nutritionists work together to discuss warning signs or symptoms that may be observed in the athlete and a devise a comprehensive nutritional plan and training program for the athlete.

- Mandatory meetings are held with nutritionists and sports psychologists who specialize in eating disorders.

- Team doctor monitors for the presence of menstrual dysfunction during physicals.

- Intervention starts with the team doctor. Coaches never try to solve the problem themselves and involve a multidisciplinary team of medical professionals.

- A comprehensive screening, assessment and educational programs are in place, supported by sports organisations and resources.

- Behavioural contracts are used to assure the athlete is compliant in behavioral changes. For example, if athletes do not keep appointments with health professionals, they cannot practice or compete.

Source: Adapted from Pantano, (2006) 
Appendix 20: Female Athlete Triad Cumulative Risk Assessment

\begin{tabular}{|c|c|c|c|}
\hline \multirow{2}{*}{ Risk Factors } & \multicolumn{3}{|c|}{ Magnitude of Risk } \\
\hline & Low Risk $=0$ points each & Moderate Risk $=1$ point each & High Risk $=2$ points each \\
\hline $\begin{array}{l}\text { Low EA with or without } \\
D E / E D\end{array}$ & $\square$ No dietary restriction & $\begin{array}{l}\square \text { Some dietary restriction;; } \\
\text { current/past history of DE; }\end{array}$ & $\begin{array}{l}\square \text { Meets DSM-V criteria for } \\
\text { ED* }^{*}\end{array}$ \\
\hline Low BMI & $\begin{array}{l}\square \text { BMI } \geq 18.5 \text { or } \\
\geq 90 \% \mathrm{EW}^{* *} \text { or } \\
\text { weight stable }\end{array}$ & $\begin{array}{l}\square \text { BMI } 17.5<18.5 \text { or } \\
<90 \% \mathrm{EW} \text { or } \\
5 \text { to }<10 \% \text { weight loss/month }\end{array}$ & $\begin{array}{c}\square \text { BMI } \leq 17.5 \text { or }<85 \% \text { EW or } \\
\geq 10 \% \text { weight loss } / \text { month }\end{array}$ \\
\hline Delayed Menarche & $\square$ Menarche $<15$ years & $\square$ Menarche 15 to $<16$ years & $\square$ Menarche $\geq 16$ years \\
\hline $\begin{array}{l}\text { Oligomenorrhea and/or } \\
\text { Amenorrhea }\end{array}$ & $\square>9$ menses in 12 months* & $\square$ 6-9 menses in 12 months* & $\square<6$ menses in 12 months* \\
\hline Low BMD & $\square$ Z-score $\geq-1.0$ & $\square$ Z-score - $1.0^{* * *}<-2.0$ & $\square$ Z-score $\leq-2.0$ \\
\hline Stress Reaction/Fracture & $\square$ None & $\square_{1}$ & $\begin{array}{c}\square \geq 2 ; \geq 1 \text { high risk or of } \\
\text { trabecular bone sites } \dagger\end{array}$ \\
\hline $\begin{array}{l}\text { Cumulative Risk } \\
\text { (total each column, then } \\
\text { add for total score) }\end{array}$ & points & __ points & $\perp_{\text {points }}={ }_{\text {T Total Score }}$ \\
\hline
\end{tabular}

The cumulative risk assessment provides an objective method of determining an athlete's risk using risk stratification and evidence-based risk factors for the Female Athlete Triad. This assessment is then used to determine an athlete's clearance for sport participation. BMD; bone mineral density; BMI; body mass index; DE; disordered eating; EA; energy availability; EW; expected weight; ED; eating disorder.

Source: De Souza et al. (2014) 
Appendix 21: Female Athlete Triad: Clearance and Return-to-Play (RTP) Guidelines by Medical Risk Stratification

\begin{tabular}{l|l|l|l|l}
\hline & $\begin{array}{l}\text { Cumulative } \\
\text { Risk Score* }\end{array}$ & Low Risk & Moderate Risk & High Risk \\
\hline Full Clearance & $0-1$ point & $\square$ & \\
\hline $\begin{array}{l}\text { Provisional/Limited } \\
\text { Clearance }\end{array}$ & $2-5$ points & $\begin{array}{l}\square \text { Provisional } \\
\text { Clearance }\end{array}$ & $\square$ Limited Clearance & $\begin{array}{l}\square \text { Restricted from } \\
\text { Training/ } \\
\text { Competition-Provisional }\end{array}$ \\
\hline $\begin{array}{l}\text { Restricted from Training } \\
\text { and Competition }\end{array}$ & $\geq 6$ points & & $\square$ Disqualified \\
\hline
\end{tabular}

Female Athlete Triad: Clearance and Return-to-Play (RTP) Guidelines by Medical Risk Stratification. *Cumulative Risk Score determined by summing the score of each risk factor (low, moderate, high risk) from the Cumulative Risk Assessment (figure 4). Clearance/RTP status for athlete's moderate-to-high risk for the Triad: provisional clearance/RTP_clearance determined from risk stratification at time of evaluation (with possibility for status to change over time depending on athlete's clinical progress); limited clearance/RTP_clearance/RTP granted, but with modification in training as specified by physician (with possibility for status to change depending on clinical progress and new information gathered); restricted from training/competition ( provisional)_athlete not cleared or able to RTP at present time, with clearance status re-evaluated by physician and multidisciplinary team with clinical progress; disqualified —not safe to participate at present time. Clearance status to be determined at future date depending on clinical progress.

Source: De Souza et al. (2014) 


\section{Appendix 22: Decision-Based Return-to-Play (RTP) Model for the Female Athlete}

Triad.

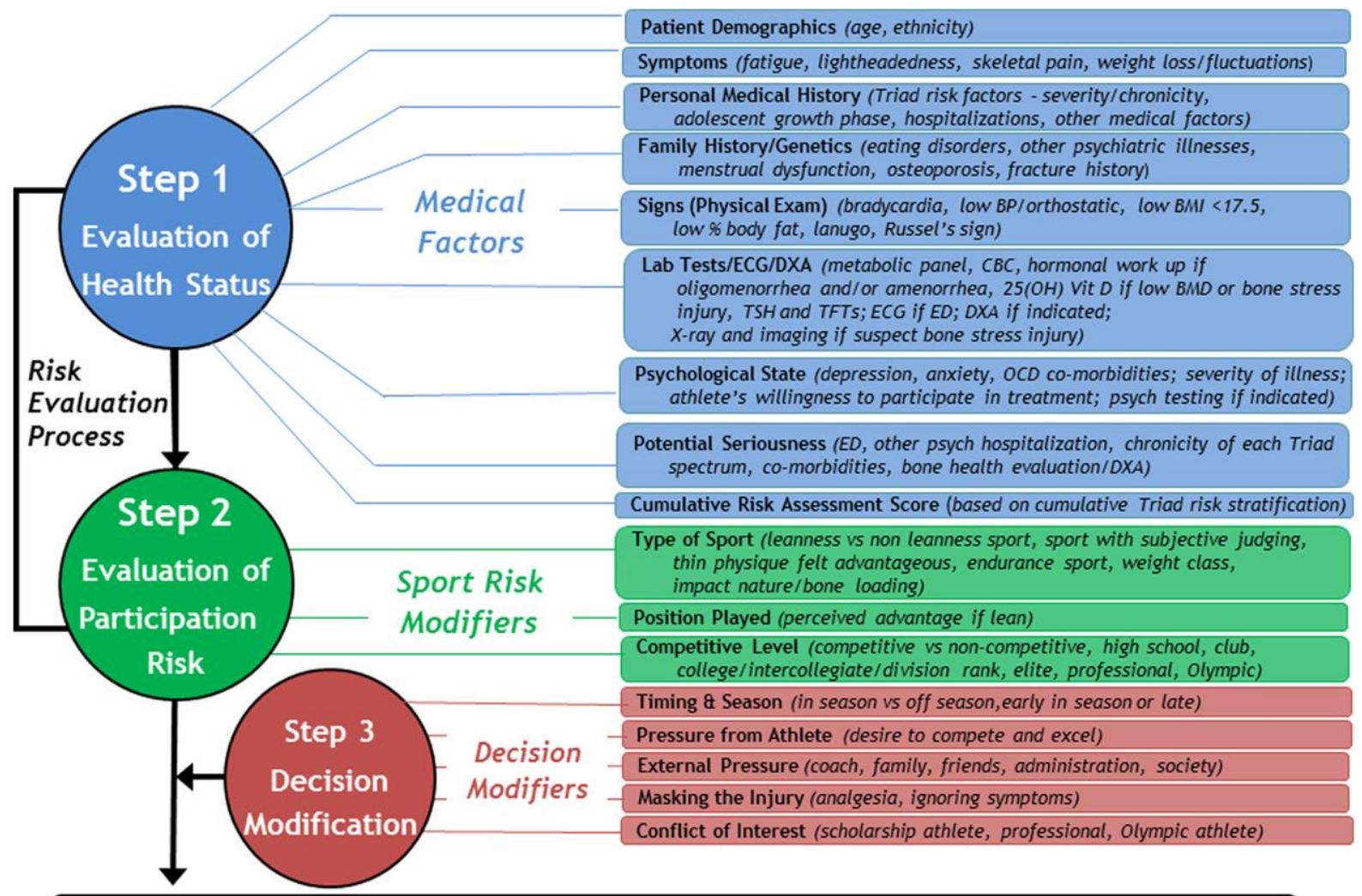

${ }^{*}$ Return-to-Play Decision

Decision-Based Return-to-Play (RTP) Model for the Female Athlete Triad. *RTP decision is determined by the primary care or team physician, and is based on a complex and comprehensive synthesis of health status, cumulative risk assessment, participation risk, sport and decision modifiers.

Source: De Souza et al. (2014) 


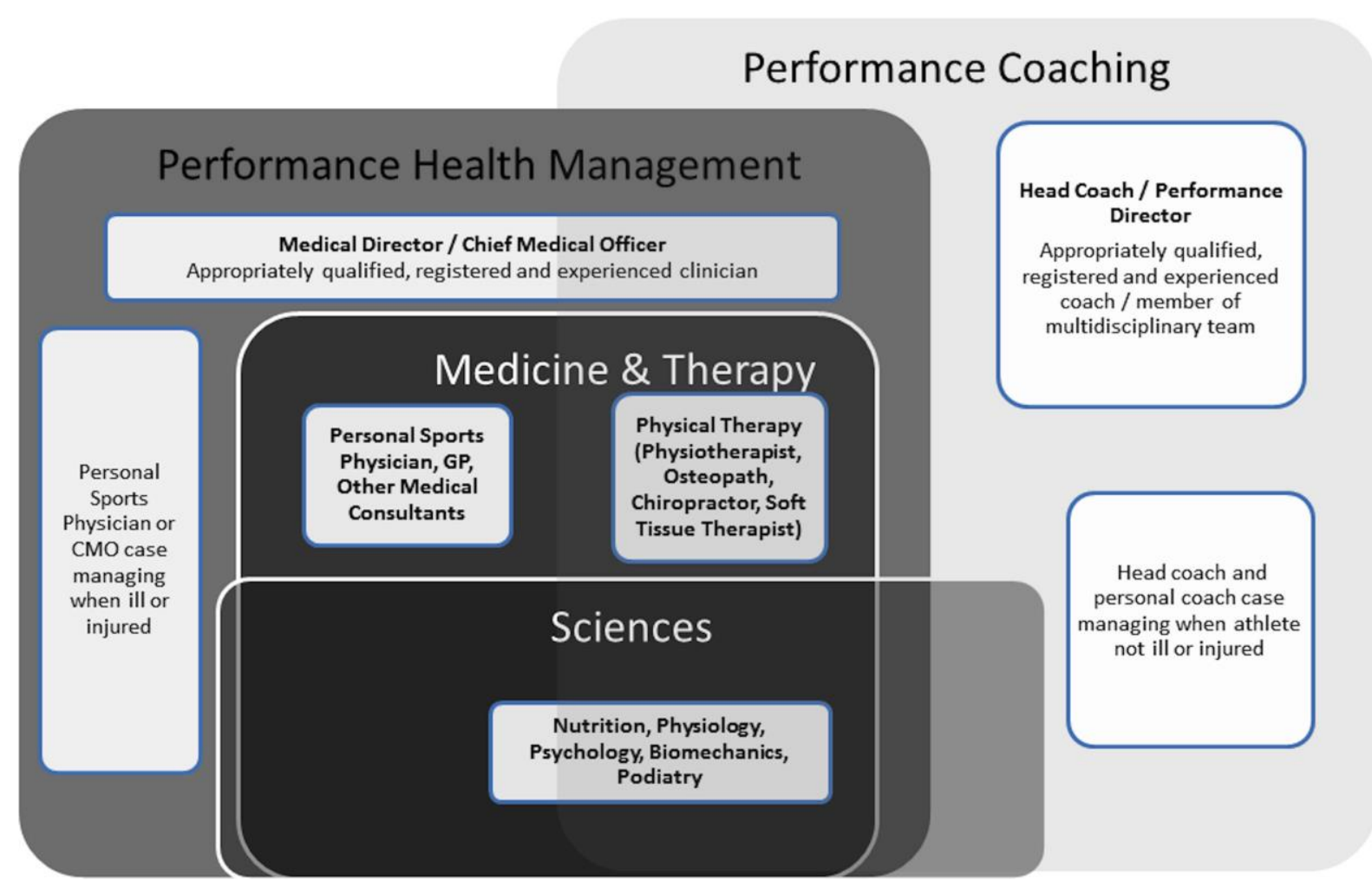

The Integrated Performance Health Management and Coaching Model. All the specialties operate in the performance health and coaching 'box'. Health (injury, illness and prevention) is managed by specialist sports medicine physicians (led by the CMO/Medical Director); coaching is managed by the Head Coach. Both departments are managed by the Performance Director or (CEO) depending on the structure and size/culture of the organisation/club. The health and coaching departments operate in synergy and also 'independently' with appropriate autonomy at times. All professional service providers are independently registered and professionally governed by the relevant Professional Bodies like the General Medical Council and the Faculty of Sport and Exercise Medicine for physicians in the UK. CEO, Chief Executive Officer; CMO, Chief Medical Officer; GP, general practitioner.

(Source: Dijiksta et al., 2014) 